\title{
A Single Stage Spool Valve for the Pressure Compensator of a Variable Displacement Pump - Design, Dynamic Simulation and Comparative Study With A Real Pump
}

Nitesh Mondal ( $\nabla$ niteshju@yahoo.com )

Techno India University

Rana Saha

Jadavpur University

Dipankar Sanyal

Jadavpur University

Original Article

Keywords: Electrohydraulic Power System, Design Technique, Modeling and Simulation, Sensitivity Analysis, Experimental Verification

Posted Date: May 18th, 2021

DOl: https://doi.org/10.21203/rs.3.rs-518623/v1

License: (c) (1) This work is licensed under a Creative Commons Attribution 4.0 International License.

Read Full License 


\title{
A single stage spool valve for the pressure compensator of a variable displacement pump - Design, dynamic simulation and comparative study with a real pump
}

\author{
Nitesh Mondal $^{1^{*}}$, Rana Saha $^{2}$, Dipankar Sanyal ${ }^{2}$ \\ ${ }^{1}$ Department of Aerospace Engineering and Applied Mechanics, Indian Institute of \\ Engineering Science and Technology, Shibpur, Howrah, India, 711103. \\ ${ }^{2}$ Department of Mechanical Engineering, Jadavpur University, Kolkata, India, 700032. \\ *Corresponding Author: niteshju@yahoo.com
}

\begin{abstract}
The study is focused on the design of a simplified spool valve to be incorporated in the pressure compensator of a variable displacement axial piston pump in order to perform a comparative study with a commercial pump having a two stage spool valve in its compensator. The design involves evaluation of the spool size and selection of spring from static equilibrium condition to satisfy cut-in and cut-off pressure. Following the development of dynamic model of the system, a design sensitivity analysis of the spool valve has been carried out through simulation to identify the critical sizes of the parameters, which affect the pump performance. By systematic design, it is possible to have a single stage spool valve controlled pressure compensator that can produce performance of the variable displacement axial piston pump at par with the similar commercially available pump.
\end{abstract}

Keywords: Electrohydraulic Power System, Design Technique, Modeling and Simulation, Sensitivity Analysis, Experimental Verification.

\section{INTRODUCTION}

The variable axial piston pump has a wide range of applications in the field of aerospace to heavy industries because of their variable displacement capabilities, high working pressures, high volumetric efficiencies, and high power densities [1, 2]. Such pumps with pressure compensator have demand in systems, where fast speed of response and power saving are of utmost importance. The power saving properties of the variable displacement axial piston pump makes the hydraulic circuit energy efficient [3]. There have been numerous research works particularly on different aspects of swash plate type axial piston pump having fixed swash angle. Ye et al. [4] developed a pump model to capture the different source of noise and introducing a damping hole in the valve plate to reduce the noise emitted from the pump. Wang [5] obtained the mathematical relation between valve plate timings and pressure carryover angles which subsequently used to investigate the containment forces and moments to address the sound properties of the pump and optimize the designs. A software based investigation had been carried out to improve the pump performance and to study the cavitation characteristic including the turbulence model, cavitation model and effect of fluid compressibility by Zhao et al. [6] through CFD simulation. Wang [7] established a strong relationship between the valve plate geometry and volumetric efficiency of an axial piston pump. Flow and pressure ripples are the major drawback for any positive displacement pump. Zheng et al. [8] numerically studied the effect of piston groove pattern and groove design on the pressure 
balance and flow through the groove ..Kemmetmuller et al. [9] gave an idea about the mathematical model and control design strategy of a nonlinear pressure controlled selfsupplied variable displacement axial piston pump, which had a single stage proportional directional control spool valve and a spring loaded actuator to control the swash angle. Wei et al. [10] used a separate pump to supply the pilot pressure to operate the spool valve and used a control cylinder with a bias spring to make the pump variable. To provide better damping and reducing the pressure gain in dynamics performance of the pump, an orifice was placed between spool valve and control cylinder by Kaliafetis et al. [11]. Zhou et al. [12] studied about dynamic lubrication between the slipper pad and swash plate experimentally for an axial piston pump. To increase the power density of a hydraulic machine Marning et al. [13] identified some significant parameters and recognized four dimensionless quantities, which helped to improve the power density of the axial piston machine. From the available previous literatures, it can be seen that there are not much works addressing the methodology to develop the control spool of the mechanism for achieving variable displacement feature of axial piston pump. In a very recent work Mondal et al. [14] formulated an innovative design procedure by developing a mathematical model for the pressure compensator of an axial piston pump. Following the same methodology, in the present work design of a rather simple single stage control spool valve has been taken up with an aim to replace the commercially used two stage valve. A parametric study has been conducted through simulation to evaluate the dynamic performance of an axial piston pump, having the designed single stage control spool valve in the compensator. The performance of the designed spool valve driven pressure compensator has been analyzed and compared both through simulation and experiment, with the performance of a commercial pump having two stage control valve. During design and development stages, analysis through simulation is preferred [15] followed by comparing with experimental results.

As shown in Fig. 1, the basic functioning of the axial piston pump is based on the reciprocation of the individual pistons housed inside a barrel and one end of it is mounted on an inclined surface known as swash plate. By the rotation of the barrel, the pistons travel over the swash plate resulting reciprocation. Each of the other ends of the pistons is exposed to barrel cylinder, which acts as the pumping chamber. The motion of the piston causes volumetric displacement of the pumping chamber, which has periodic connections with suction and delivery manifolds through a disc known as valve plate. The algebraic sum of discharge through each piston results overall delivery flow rate of the pump. For a fixed displacement pump, the volumetric displacement per rotation remains constant, while that can be varied by appropriate mechanism in a variable displacement pump. Such mechanism for an axial piston pump is known as pressure compensator.

The pressure compensator arrangement of this pump consists of a single stage control spool valve and two actuators acting in opposite manner against the swash plate at the two ends. The balancing of torque on the swash plate produced by these actuator pistons and the barrel pistons of the pump at different swash angle is the basic principle behind variable displacement operation of the pump. One of the actuators, called the stroking cylinder is connected to the delivery line of the pump through the spool valve. The other spring loaded actuator, termed as the rate cylinder, is also connected to the delivery manifold of the pump. So there is a pressure feedback to the upstream side of the rate piston and this type of arrangement is called rate feedback. The objective of this 
arrangement is to go for a much lower stiffness spring on the rate cylinder. The pre-set compression of the spring in the rate cylinder determines the swash angle corresponding to which the pump has a rated pressure and discharge. Change in swash angle thereby the variable displacement feature of such a pump depends on the commencement of the displacement of a spool valve $[\mathbf{1 0}, \mathbf{1 6}]$. The activation of the spool valve is controlled by a reference delivery pressure also known as the pilot pressure of the spool valve, which is governed by the pre-compression of a spring fitted at the end of spool valve. This reference pressure is also known as cut-in pressure of the system beyond which the spool ports begin to open so that pressurized oil comes from delivery manifold to stroking cylinder through metered opening of spool valve. The high pressure oil acts on the stroking piston to produce additional torque on the swash plate causing unbalance to the equilibrium. As a result the swash plate starts rotating in the direction of the applied additional torque. Therefore, the swash angle gets reduced causing further compression in the spring of the rate piston. The presence of high pressure oil in the rate cylinder along with compression in the spring causes the opposing torque to increase that ultimately will ensure a new equilibrium. A situation will arise, when the swash angle becomes minimum at equilibrium. The delivery pressure at that condition is known as cut-off pressure. Since the swash angle governs the swept volume of the barrel piston, minimum swash angle will correspond to minimum flow rate of the pump at maximum pressure (cut-off). This will result minimum power loss, which otherwise will be maximum if using a pressure relief valve with a fixed displacement pump.

Following the methodology proposed in an earlier work [14], the present work has been organised first by focusing on the design of a single stage spool valve for the pressure compensator of pump. The design involves evaluation of the spool size and selection of spring from static equilibrium condition to satisfy cut-in and cut-off pressure. Following the development of dynamic model of the system with subsequent implementation in MATLAB/SIMULINK environment, other parameters of the spool valve that could affect the performance of the pump have been evaluated through dynamic simulation. Results obtained from simulation for the present design has been compared with a commercial pump (A10VSO45 series pump from Rexroth) [17] having compensator with double spool in order to study the effectiveness of the simplified compensator design. 


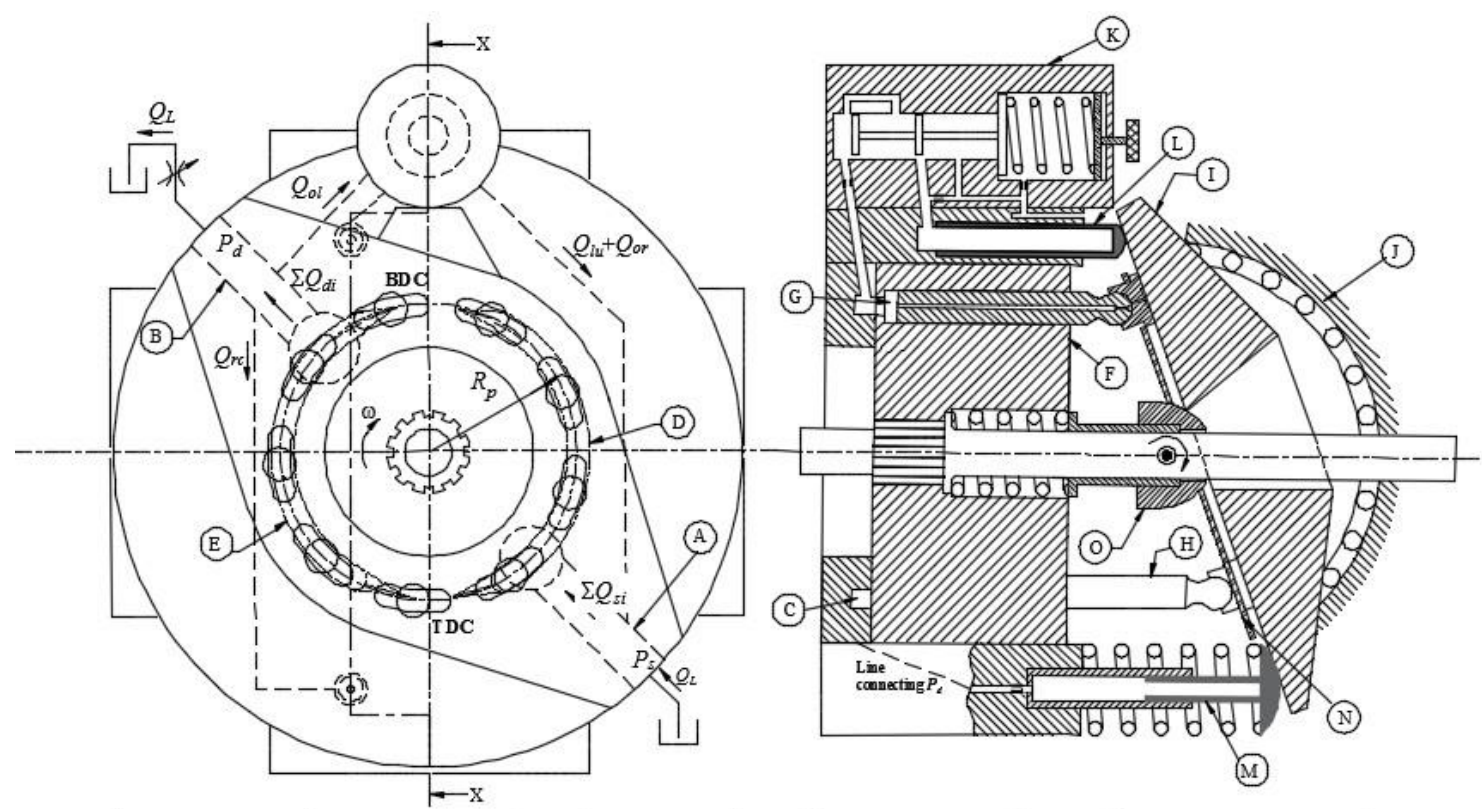

A:Suction Port B:Delivery Port C: Valve Plate D:Suction Kidney Port E:Delivery Kidney Port F: Barrel G: Barrel Bore $\mathrm{H}$ : Barrel Piston $\mathrm{N}$ :Retainer O: Bush

Fig. 1 Schematic of a swash-plate axial piston pump with pressure compensator

\section{DESIGN OF SPOOL VALVE FROM STATIC CONDITION}

The spool valve is the key element in the pressure compensator. The performance of the spool valve governs the characteristics of variable displacement axial piston pump. Following are the considerations for the design of spring and spool land of the spool valve, the schematic of which is shown in Fig. 2.

a) The spool displacement starts at cut-in pressure $P_{d c i}$, and attains its maximum displacement at the cut-off pressure $P_{d c o}$.

b) The flow force $F_{s}$, acting on the spool is neglected under static condition.

c) The effect of radial clearance is neglected.

In static condition at the cut-in limit, the active pressure $P_{d}^{*}$ acting at the left side of the spool remains at $P_{d c i}$, whereas the back pressure $P_{l}$ acting on the right side of the spool remains at the case pressure $P_{r}$. Under this situation the hydraulic force on the spool should be balanced by the spring force due to a spring pre-compression $\delta_{s 0}$ leading to the relation

$$
\left(P_{d c i}-P_{r}\right)\left(\pi d_{s}^{2} / 4\right)=k_{s} \delta_{s 0} .
$$

For a realistic choice, following the previous approach of Mondal et al.[14], of both the spool land diameter, $d_{s}$ and spring pre-compression, $\delta_{s 0}$, the spring stiffness $k_{s}$ has been estimated. A feasible size of the spring in terms of coil diameter, wire diameter, number of coil turns has been selected using a well-known relation [18] so as to match the estimated stiffness. The equation is

$$
k_{s}=\frac{G d^{4}}{8 D^{3} n},
$$

where $G$ is the modulus of rigidity of the spring material, $d$ is the wire diameter, $D$ is the mean coil diameter and $n$ is the number of turns. 
In order to accommodate the available spring, necessary modifications in terms of increase in the right side spool land diameter and the chamber length have been done. It can be observed that this diameter $d_{s r}$ could be larger than the diameters $\left(d_{s}\right)$ of the other two lands. However, this increase in size would not alter the force balance equation as long as both sides of this land experience the case pressure $P_{r}$, typically for the situation under static condition.

The maximum spool displacement, which is also the maximum spring compression, is obtained from the static force balance at cut-off condition given by

$$
P_{d c o}\left(\pi d_{s}^{2} / 4\right)-P_{r}\left(\pi d_{s r}^{2} / 4\right)=k_{s}\left(\delta_{s 0}+x_{s v \max }\right) .
$$

Table 1 lists the parameters some of which has been chosen from the earlier experience [14], while others are obtained from the above conditions.

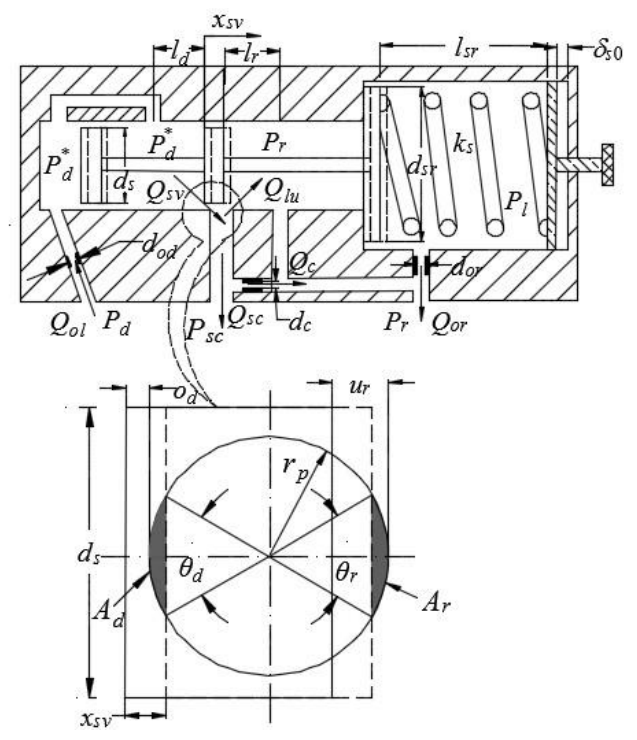

Fig. 2 Schematic of the single-stage control spool valve

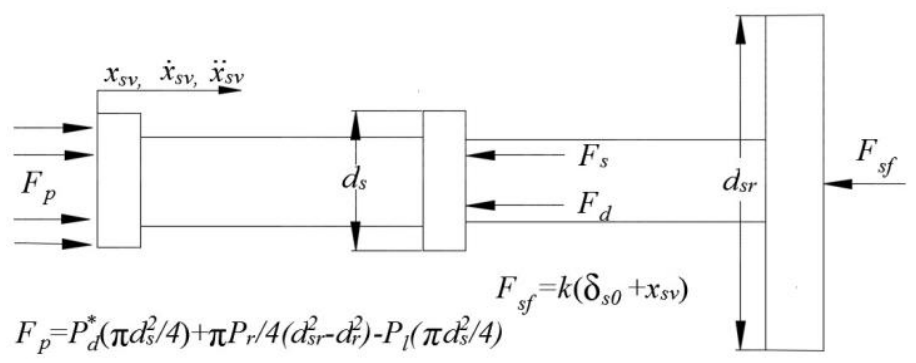

Fig. 3 Free body diagram of the spool 
Table 1 Parameter values for the designed pressure compensator

\begin{tabular}{cccc}
\hline \hline $\begin{array}{c}\text { Parameter } \\
\text { (Chosen) }\end{array}$ & Value & $\begin{array}{c}\text { Parameter } \\
\text { (obtained) }\end{array}$ & Value \\
\hline$d_{s}$ & $6.5 \times 10^{-3} \mathrm{~m}$ & $k_{s}$ & $68786 \mathrm{~N} / \mathrm{m}$ \\
$\delta_{s 0}$ & $8.6 \times 10^{-3} \mathrm{~m}$ & $x_{s v \max }$ & $2.408 \times 10^{-4} \mathrm{~m}$ \\
$G$ & $\begin{array}{c}79.3 \times 10^{9} \\
\mathrm{~Pa}\end{array}$ & $d_{s r}$ & $20.5 \mathrm{~m}$ \\
& $4 \times 10^{-3} \mathrm{~m}$ & $D$ & $16 \times 10^{-3} \mathrm{~m}$ \\
$d$ & 8 & & \\
$n$ &
\end{tabular}

\section{DYNAMIC MODEL OF THE COMPENSATOR SYSTEM}

\subsection{Spool Valve Dynamics}

As shown in Fig. 2, the left side of the spool valve is connected to the delivery side of the pump through an entry orifice of diameter $d_{o d}$, due to which the pressure remains at $P_{d}^{*}$ instead of delivery pressure $P_{d}$. The right end side of the spool is connected to the reservoir through an orifice of diameter $d_{o r}$, due to which the pressure remains at $P_{l}$ instead of reservoir pressure $P_{r}$. The chamber between the middle and right land of the spool valve is directly connected to the reservoir, thereby considered to experience the same reservoir pressure. This pressure acting on both the opposing surfaces will not result any net force acting on the spool. Under these considerations and with reference to Fig. 3, the spool displacement equation, in terms of the conditions between the net hydraulic pressure force $F_{p}$ and the spring force $F_{s f}$, can be written as

$$
\begin{gathered}
\ddot{x}_{s v}=0 \text { for } F_{p} \leq k_{s} \delta_{s 0}, \\
\ddot{x}_{s v}=\left(F_{p}-F_{d}-F_{s}-F_{s f}\right) / m_{s v} \text { for } F_{p}>k_{s} \delta_{s 0},
\end{gathered}
$$

where $F_{d}$ is the transient flow force and $F_{s}$ is the steady flow force acting on the spool expressed respectively from Merrit [19] as

$$
\begin{gathered}
F_{d}=\rho\left(l_{d} \dot{Q}_{s v}-l_{r} \dot{Q}_{l u}\right), \\
F_{s}=2 C_{d} C_{v}\left\{A_{d}\left(P_{d}^{*}-P_{s c}\right) \cos \theta_{j d}+A_{r}\left(P_{s c}-P_{r}\right) \cos \theta_{j r}\right\},
\end{gathered}
$$

where $C_{d}$ and $C_{v}$ are the coefficients of discharge and velocity respectively, $l_{d}$ and $l_{r}$ are the two damping lengths as shown in Fig. 2. The two metered flows $Q_{s v}$ from the spool valve to the stroking cylinder and $Q_{l u}$ to the return chamber from the stroking cylinder can be expressed in terms of the respective pressure drops as

$$
\begin{gathered}
Q_{s v}=C_{d} A_{d} \sqrt{2\left(P_{d}^{*}-P_{s c}\right) / \rho} \operatorname{sgn}\left|P_{d}^{*}-P_{s c}\right|, \\
\text { and } Q_{l u}=C_{d} A_{r} \sqrt{2\left(P_{s c}-P_{r}\right) / \rho} \operatorname{sgn}\left|P_{s c}-P_{r}\right|,
\end{gathered}
$$

where $\theta_{j d}$ and $\theta_{j r}$ are respectively the jet angles of the metered flows $Q_{s v}$ and $Q_{l u}$. Assuming near-zero radial clearance both the jet angles are assigned as $69^{\circ}$ from Merrit [19]. From the geometry shown in Fig. 2, the variable opening areas $A_{d}$ and $A_{r}$ due to the spool displacement can be expressed as

$$
A_{d}=n_{p} r_{p}^{2}\left\{\theta_{d}-\left(\sin \theta_{d}\right)\right\} / 2,
$$




$$
\text { and } A_{r}=n_{p} r_{p}^{2}\left\{\theta_{r}-\left(\sin \theta_{r}\right)\right\} / 2,
$$

for $n_{p}$ numbers of circular port cuts of radius $r_{p}$, where as $\theta_{d}$ and $\theta_{r}$ are the angles subtended by the intersections of the spool land with the circular port cut at the delivery and return sides respectively as shown in the expanded view in Fig. 2. For a spool displacement $x_{s v}$, overlap $o_{d}$ at the delivery side and underlap $u_{r}$ at the return side, these angles can be obtained as

$$
\begin{aligned}
\theta_{d} & =2 \cos ^{-1}\left\{1-\max \left(x_{s v}-o_{d}, 0\right) / r_{p}\right\}, \\
\text { and } \theta_{r} & =2 \cos ^{-1}\left\{1-\max \left(u_{r}-x_{s v}, 0\right) / r_{p}\right\} .
\end{aligned}
$$

Considering compressibility effect, the dynamics of the pressure $P_{d}^{*}$ in the left chamber of the spool valve can be expressed in terms of the velocity of the spool, flow rate through the entry orifice, bulk modulus of the working fluid and dead volume of the chamber as

$$
\dot{P}_{d}^{*}=\beta\left\{Q_{o l}-\pi\left(d_{s}^{2} / 4\right) \dot{x}_{s v}\right\} /\left\{v_{0}+\pi\left(d_{s}^{2} / 4\right) x_{s v}\right\},
$$

in which the flow rate $Q_{o l}$ through the entry orifice of diameter $d_{o d}$ can be expressed as

$$
Q_{o l}=C_{d}\left(\pi d_{o d}^{2} / 4\right) \sqrt{2\left(P_{d}-P_{d}^{*}\right) / \rho} \operatorname{sgn}\left|P_{d}-P_{d}^{*}\right| .
$$

In case, the pressure in the left chamber of the spool valve is considered same as the delivery pressure of the valve, the flow rate $Q_{o l}$ can be found using continuity equation inside the chamber considering incompressible flow as

$$
Q_{o l}=\pi\left(d_{s}^{2} / 4\right) \dot{x}_{s v} \text {. }
$$

In a ploy to achieve damping in the spool motion, an orifice of diameter $d_{o r}$ is provided in the drain side of the spool valve as shown in Fig. 2, such that a back pressure $P_{l}$ is developed at the return side chamber due to which a force acts on the rightmost spool land opposing the spool motion as written in Eq. (3b). In terms of the spool motion and bulk modulus $\beta$, the dynamics of this back pressure is expressed as

$$
\left.\dot{P}_{l}=\beta\left\{\pi\left(d_{o r}^{2} / 4\right) \dot{x}_{s v}-Q_{o r}\right)\right\} /\left\{\pi\left(d_{o r}^{2} / 4\right)\left(l_{s r}-x_{s v}\right)\right\},
$$

where $l_{s r}$ is the length of the rightmost spool chamber after the pre-compression that can be evaluated from the knowledge of the free length of the spring selected through static design and the amount of pre-compression and $Q_{o r}$ is the flow through this damping orifice given by

$$
Q_{o r}=C_{d}\left(\pi d_{o r}^{2} / 4\right) \sqrt{2\left(P_{l}-P_{r}\right) / \rho} \operatorname{sgn}\left|P_{l}-P_{r}\right|,
$$

In case, the back pressure is considered same as the case pressure of $P_{r}$, the flow rate $Q_{o r}$ can be found using continuity equation inside the chamber considering incompressible flow as

$$
Q_{o r}=\pi\left(d_{o r}^{2} / 4\right) \dot{x}_{s v} \text {. }
$$

Satisfying continuity across the valve, the flow $Q_{s c}$ entering to the stroking cylinder from the spool valve that can be written from Fig. 2 as,

$$
Q_{s c}=Q_{s v}-Q_{l u}-Q_{c},
$$

where $Q_{c}$ is the flow through the clearance orifice of diameter $d_{c}$ of the spool valve that can be expressed as

$$
Q_{c}=c_{d}\left(\pi d_{c}^{2} / 4\right) \sqrt{2\left(P_{s c}-P_{r}\right) / \rho} \operatorname{sgn}\left|P_{s c}-P_{r}\right|,
$$

while, $Q_{s v}$ and $Q_{l u}$ have already modelled in Eqs. (4c) and (4d).

Of course, there is a direct interaction of the spool valve dynamics with the swivelling dynamics of the swash plate including the rate and stroking cylinders of the pressure 
compensator. The mathematical model for the dynamics of the pressure compensator are elaborated next, with reference to Fig.4, keeping the static design of rate and stroking cylinder same as in the previous work by Mondal et al. [14].

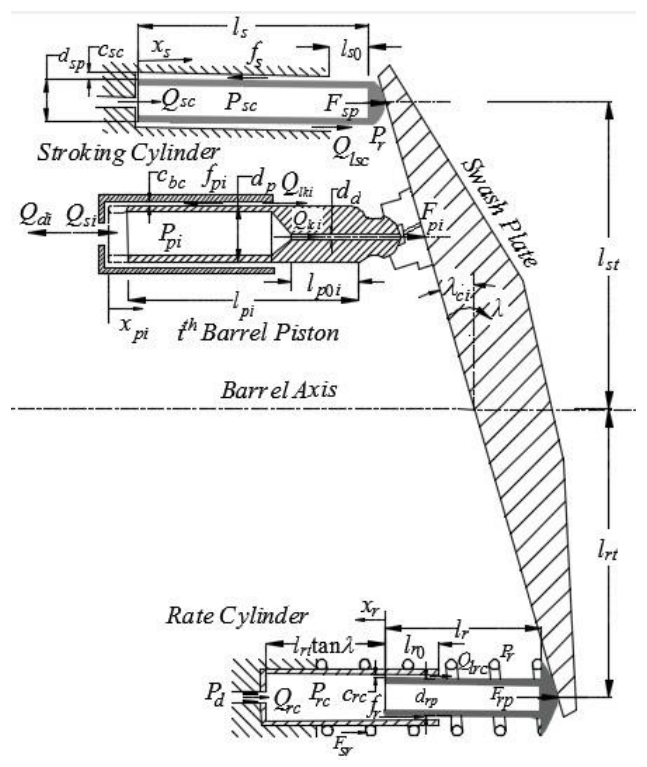

Fig. 4 Cylinders position against swash plate

\subsection{Modeling of Swash Plate and Associated Motion Dynamics}

When the delivery pressure goes beyond the cut in pressure, the displacement of the spool in the valve sets in and a coupled dynamics of motion takes place amongst the stroking piston, rate piston, barrel pistons and the swash-plate with mass moment of inertia $I_{s w}$. Figure 4 represents such an arrangement of the swash plate in which one barrel piston $\left(i^{\text {th }}\right.$ barrel $)$ is shown representatively. The equation of the swivelling dynamics to find out the instantaneous swash angle $\lambda$, can be derived with reference to this figure and is expressed as

$$
\begin{gathered}
\left(I_{s w}+m_{s} l_{s t}^{2}+m_{r} l_{r t}^{2}\right) \ddot{\lambda} \\
=F_{s p} l_{s t}-F_{r p} l_{r t}+\sum_{i=1}^{9}\left[\left(F_{p i}-m_{p} \ddot{x}_{p i}\right)\left\{R_{p} \cos (\omega t+2 \pi(i-1) / 9)\right\}\right],
\end{gathered}
$$

where $l_{s t}$ and $l_{r t}$ are the distances from the barrel axis to stroking cylinder and rate cylinder respectively. $R_{p}$ is the pitch circle radius of the barrel and $\omega$ is the angular speed of the barrel. The initial value of the swash angle is considered as $\lambda_{c i}$.

The angular motion of the swash plate and the linear motions of the stroking and rate pistons are correlated through angular acceleration of the swash plate and the respective radii of curvatures $l_{s t}$ and $l_{r t}$, as

$$
\begin{gathered}
\ddot{x}_{s}=l_{s t} \ddot{\lambda}, \\
\text { and } \ddot{x}_{r}=l_{r t} \ddot{\lambda} .
\end{gathered}
$$

The acceleration $\ddot{x}_{p i}$ of the $i^{\text {th }}$ barrel piston can be obtained from the instantaneous position $x_{p i}$ of the piston, which is expressed in terms of the variable swash angle $\lambda$ and the speed of barrel rotation $\omega$ as

$$
x_{p i}=R_{p}[1-\cos \{\omega t+2 \pi(i-1) / 9\}] \tan \lambda .
$$


In Eq. (10a), $F_{s p}, F_{r p}$ and $F_{p i}$ are the combined forces other than inertia acting respectively on the stroking, rate and $i^{\text {th }}$ barrel piston. In general, this force, $F_{n e t}$ is composed of pressure force, $f_{h y d}$, viscous friction force, $f_{r i c}$ and spring force, $f_{s p r}$ if any, so as to write

$$
F_{\text {net }}=f_{\text {hyd }}+f_{\text {fric }}+f_{\text {spr }} \text {. }
$$

The force components of the above equation for the respective pistons are furnished, with reference to Fig. 4, in Table 2. The sense of any force is considered positive for the direction left to right. All the notations used in Table 2 are shown in Fig.4, which are selfexplanatory.

Table 2 Composition of forces for different pistons

\begin{tabular}{lccll}
\hline Piston & $F_{n e t}$ & \multicolumn{1}{c}{$f_{\text {hyd }}$} & \multicolumn{1}{c}{$f_{f r i c}$} & \multicolumn{1}{c}{$f_{s p r}$} \\
\hline Stroking & $F_{s p}$ & $\left(P_{s c}-P_{r}\right)\left(\pi d_{s p}^{2} / 4\right)$ & $-\pi \mu d_{s p}\left(l_{s}-l_{s 0}-x_{s}\right) \dot{x}_{s} / c_{s c}$ & No spring \\
Rate & $F_{r p}$ & $\left(P_{r c}-P_{r}\right)\left(\pi d_{r p}^{2} / 4\right)$ & $\pi l d_{r p}\left(l_{r 0}+x_{r}\right) \dot{x}_{r} / c_{r c}$ & $k_{r}\left(\delta_{0}+x_{r}\right)$ \\
$i^{\text {th }}$ Barrel & $F_{p i}$ & $\left(P_{p i}-P_{r}\right)\left(\pi d_{p}^{2} / 4\right)$ & $-\pi l d_{p} \dot{x}_{p i}\left(l_{p i}-l_{p 0 i}-x_{p i}\right) / c_{b c}$ & No spring \\
\hline \hline
\end{tabular}

\subsection{Modeling of Pressure Dynamics inside the Cylinders}

The stroking, rate and barrel are the three types of cylinders in the pump that have their pistons reciprocating inside, thereby causing volumetric changes. Due to this motion, the respective pressure inside the cylinder chamber will have a dynamics that can be modelled considering compressibility of the oil. From the definition of bulk modulus, the rate of change of pressure inside a changing volume $V$, which is having an inlet flow $Q_{i n}$ and leakage flow from the volume $Q_{\text {leak }}$, can be expressed as,

$$
\dot{P}_{c y l}=\beta\left(Q_{\text {in }}-Q_{\text {leak }}-\dot{V}\right) / V \text {. }
$$

in which $Q_{\text {leak }}$ is composed of the flow through the clearance between piston and cylinder. Hydraulic oil leakage has significant effect on the pump efficiency and the leakage depends on the pressure [20]. Only in case of the barrel there will be an additional leakage path for the supply of oil to the interface of piston shoe and slipper pad. Considering fully developed laminar flow through these passages, the respective leakage flow rates given in Table 3 can be expressed in general from $[\mathbf{2 1}, \mathbf{2 2}]$ as

$$
\begin{gathered}
Q_{l s c}=\left(\pi d_{s p} c_{s c}^{3}\right)\left(P_{s c}-P_{r}\right) /\left\{12 \mu\left(l_{s}-l_{s o}-x_{s}\right)\right\}, \\
Q_{l r c}=\left(\pi d_{r p} c_{r c}^{3}\right)\left(P_{r c}-P_{r}\right) /\left\{12 \mu\left(l_{r o}+x_{s} l_{r t} / l_{s t}\right)\right\}, \\
Q_{l k i}=\left(\pi d_{p} c_{b c}^{3}\right)\left(P_{p i}-P_{r}\right) /\left\{12 \mu\left(l_{p i}-l_{p 0 i}-x_{p i}\right)\right\}, \\
\quad \text { and } Q_{l c i}=\left(\pi d_{d}^{4}\right)\left(P_{p i}-P_{r}\right) /\left(128 \mu l_{b}\right) .
\end{gathered}
$$

The pressure terms other than the case pressure involved in Eq. (11) and Table 2 can be obtained by solving Eqs. (12) and (13), where the respective terms are elaborated in Table 3 with reference to Fig. 4. 
Table 3 Cylinder wise terms involved in the respective pressure dynamics

\begin{tabular}{lccccc}
\hline \hline Cylinder & $P_{c y l}$ & $Q_{i n}$ & $Q_{l e a k}$ & $\dot{V}$ & $V$ \\
\hline Stroking & $P_{s c}$ & $Q_{s c}$ & $Q_{l s c}$ & $(\pi / 4) d_{s p}^{2} \dot{x}_{s}$ & $\left(\pi d_{s p}^{2} / 4\right)\left(l_{s}+x_{s}\right)$ \\
Rate & $P_{r c}$ & $Q_{r c}$ & $Q_{l r c}$ & $-(\pi / 4) d_{r p}^{2} \dot{x}_{r}$ & $\left(\pi d_{r p}^{2} / 4\right)\left(l_{r}+l_{r t} \tan \lambda_{c i}-x_{r}\right)$ \\
$i^{\text {th }}$ Barrel & $P_{p i}$ & $Q_{s i}-Q_{d i}$ & $Q_{l c i}+Q_{l k i}$ & $-(\pi / 4) d_{p}^{2} \dot{x}_{p i}$ & $\left(\pi d_{p}^{2} / 4\right)\left(l_{p i}-l_{p 0 i}+x_{p i}\right)$ \\
\hline
\end{tabular}

In Table 3, the inlet flow $Q_{s c}$ has already been defined in Eq. (9a), whereas $Q_{r c}$ is the flow coming from the delivery line of the pump to the rate cylinder through an orifice of area $A_{0}$ given by

$$
Q_{r c}=c_{d} A_{0} \sqrt{2\left(P_{r c}-P_{r}\right) / \rho} \operatorname{sgn}\left|P_{r c}-P_{r}\right| \text {. }
$$

Now $Q_{d i}$ and $Q_{s i}$ are the delivery and suction flow rate of $i^{\text {th }}$ pump barrel. The engagement of $i^{\text {th }}$ barrel cylinder during its reciprocation with the respective manifolds, results in delivery and suction flow rates given respectively as

$$
\begin{gathered}
Q_{d i}=C_{d} A_{d i} \sqrt{2\left|P_{p i}-P_{d}\right| / \rho} \operatorname{sgn}\left|P_{p i}-P_{d}\right| . \\
\text { and } Q_{s i}=C_{d} A_{s i} \sqrt{2\left|P_{s}-P_{p i}\right| / \rho} \operatorname{sgn}\left|P_{s}-P_{p i}\right| .
\end{gathered}
$$

where the respective engaged areas $A_{d i}$ and $A_{s i}$ are at delivery and suction sides. The variation of these areas with barrel rotation are obtained following the methodology used in Mandal et al. [16, 23].

\subsection{Modeling of Pressure and Flow External to the Pump}

The dynamics of pressures $P_{d}$ and $P_{s}$ in the respective delivery and suction manifolds can be obtained by considering compressibility effect in the volume $V_{p d}$ between delivery port and load orifice upstream and the volume $V_{p s}$ of reservoir and suction port together. Assuming no leakage outside the pump, it is considered that the flow coming out from the load orifice $Q_{L}$ re-enters the pump through the suction manifold. Hence, with reference to Fig. 1, the pressure rates can be expressed as

$$
\begin{gathered}
\dot{P}_{d}=\beta\left[\sum_{i=1}^{n} Q_{d i}-Q_{L}-Q_{r c}-Q_{o l}\right] / V_{p d} \\
\text { and } \dot{P}_{s}=\beta\left[Q_{L}+Q_{l u}+Q_{o r}-\sum_{i=1}^{n} Q_{s i}\right] / V_{p s}
\end{gathered}
$$

Now, the flow through the load orifice of area $A_{L}$ can be expressed as

$$
Q_{L}=C_{d} A_{L} \sqrt{2\left(P_{d}-P_{r}\right) / \rho}
$$

To evaluate the dynamic performance of the pump the additional parameters used in simulation are furnished in Table 4.

\section{PARAMETER SIZING THROUGH SIMULATION}

Axial piston pumps are beneficial in terms of compactness and reliability [24]. There are various parameters that have significant influence in pump performance. The dynamic model of the compensator system and the pump described in the earlier section through Eqs. (3) to (19) have been coded as a Matlab/Simulink (version 8.0) model. The model is being run using ODE4 (Runge-Kutta) solver with fixed time step of $2.5 \times 10^{-7} \mathrm{~s}$. Apart 
from using the parameter values listed in Table 1 and 4 , the input required to run the simulation are the speed of barrel rotation $\omega$ and the loading condition of the pump represented by the area $A_{L}$ of the load orifice in Eq. (19). Unless otherwise mentioned, for all the simulation and experiment exercises, the load orifice area is set initially at a value that corresponds to the near cut-in delivery pressure of $19 \mathrm{MPa}$. This area is retained for up to 30ms after which for the next $40 \mathrm{~ms}$, the area is decreased linearly towards full closure and maintaining it for $40 \mathrm{~ms}$ targeting the cut-off condition. After that the area is increased in a same linear manner such that the pump will return back to its cut-in condition. Figure 5 shows the typical variation of the load orifice area, which has been input to the simulation model. The speed of barrel rotation is set at $1500 \mathrm{rpm}$, same as measured in the experimental setup. In this section the design analysis of single stage spool has been carried out and the pressure dynamics of the pump has been validated with the simulation performance in terms of pressure of the pump which has a compensator with double spool and the experimental pressure dynamics of the pump which also has double stage spool valve.

Table 4 Additional parameters required for dynamic simulation

\begin{tabular}{cccc}
\hline \hline Parameter & Value & Parameter & Value \\
\hline$A_{0}$ & $1.767 \times 10^{-6} \mathrm{~m}^{2}$ & $l_{r 0}$ & $10 \times 10^{-3} \mathrm{~m}$ \\
$A_{L}$ & $8.66 \times 10^{-5} \mathrm{~m}^{2}$ & $l_{s}$ & $48 \times 10^{-3} \mathrm{~m}$ \\
$C_{b c}$ & $11 \mu \mathrm{m}$ & $l_{s 0}$ & $5 \times 10^{-3} \mathrm{~m}$ \\
$C_{r c}$ & $70 \mu \mathrm{m}$ & $l_{s r}$ & $41.5 \times 10^{-3} \mathrm{~m}$ \\
$C_{s c}$ & $39 \mu \mathrm{m}$ & $l_{s t}, l_{r t}$ & $50 \times 10^{-3} \mathrm{~m}$ \\
$d_{r p}$ & $9 \times 10^{-3} \mathrm{~m}$ & $m_{p}$ & $0.0306 \mathrm{~kg}$ \\
$d_{s p}$ & $12.85 \times 10^{-3} \mathrm{~m}$ & $m_{r}$ & $0.052 \mathrm{~kg}$ \\
$I_{s}$ & $985.992 \times 10^{-9} \mathrm{~kg}-\mathrm{m}^{2}$ & $m_{s}$ & $0.041 \mathrm{~kg}$ \\
$l_{b}$ & $15 \times 10^{-3} \mathrm{~m}^{2}$ & $m_{s v}$ & $0.02 \mathrm{~kg}$ \\
$l_{d}, l_{r}$ & $15 \times 10^{-3} \mathrm{~m}$ & $O_{d}, u_{r}$ & $10 \mu \mathrm{m}, 90 \mu \mathrm{m}$ \\
$l_{p i}$ & $65.5 \times 10^{-3} \mathrm{~m}$ & $R_{p}$ & $35 \times 10^{-3} \mathrm{~m}$ \\
$l_{p 0 i}$ & $10 \times 10^{-3} \mathrm{~m}$ & $V_{d p}$ & $1.44 \times 10^{-3} \mathrm{~m}^{3}$ \\
$l_{r}$ & $35 \times 10^{-3} \mathrm{~m}$ & $V_{p s}$ & $0.714 \mathrm{~m}^{3}$ \\
\hline \hline
\end{tabular}

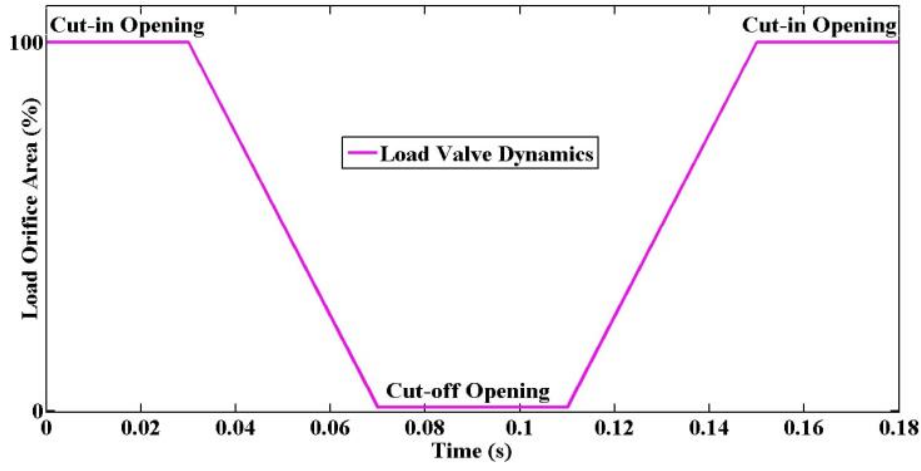

Fig. 5 Loading pattern to the axial piston pump by changing orifice area 


\subsection{Effect of Considering Compressibility Model at Delivery Chamber of Spool Valve}

Before the parametric study, the need of considering separate pressure node $P_{d}^{*}$ at the delivery chamber of the spool valve has been studied. Such consideration calls for inclusion of Eqs. (7a) and (7b) in the simulation and termed as compressible model while if the delivery chamber of the valve is considered to remain same as delivery pressure $P_{d}$, of the pump, the same is termed as incompressible. In such case, Eqs. (7a) and (7b) need to be replaced by Eq. (7c) in the simulation. The study has been done in terms of observing the predictions of delivery pressure, spool displacement and pressure inside the stroking cylinder for the loading pattern mentioned above. Figure 6 shows the comparison between the two modeling approaches. It can be seen that there are hardly any differences in the predictions following the two different methods. However, in order to evaluate the size of the entry orifice, depicted in the next section, the compressible model has been used.
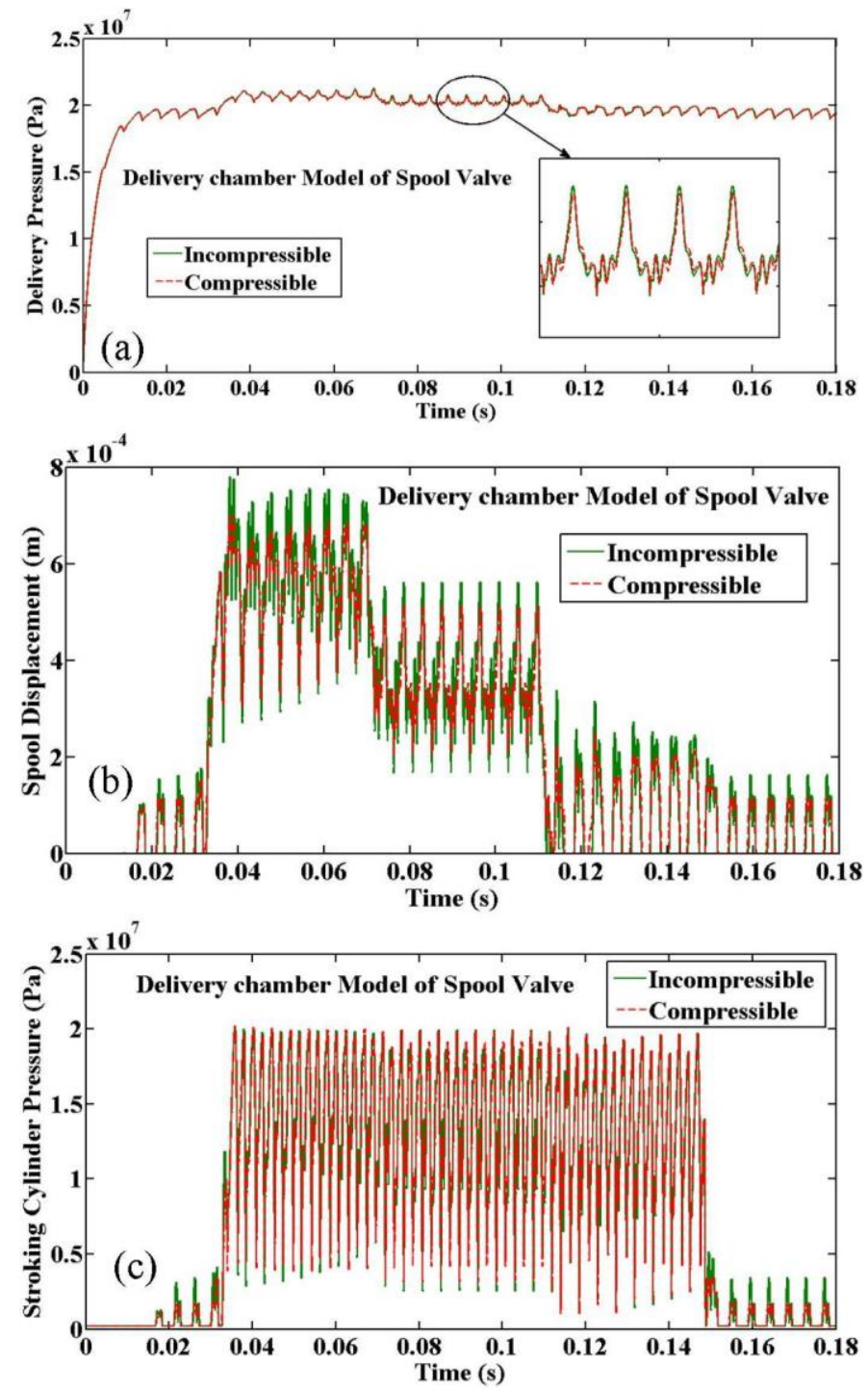

Fig. 6 Effect of compressible model in the extreme left chamber of the spool valve 


\subsection{Evaluation of the Size of Entry Orifice to the Spool Valve}

Figure 7 depicts the performance of the pump for different delivery orifice at the spool valve. This orifice acts as a bridge element between the pump and the spool valve. The delivery line of the pump is connected to the spool valve through this orifice. The diameter of the orifice has been varied from zero to $1 \mathrm{~mm}$ and the performance of the pump has been predicted in terms of delivery pressure, swash angle and flow rate characteristics of the pump for the same loading pattern shown in Fig. 5. Of course in Fig.7 zero size orifice is indicated as 'no orifice' in which the left spool chamber is directly connected with the pump. It is clear from the figure that there is very little difference in terms of the performance of the pump with or without having an orifice at the entry of the spool valve. Hence, for the spool valve, no entry orifice has been suggested and accordingly for the rest of the study, incompressible model has been used at the delivery chamber of the spool valve for it takes less simulation runtime. 

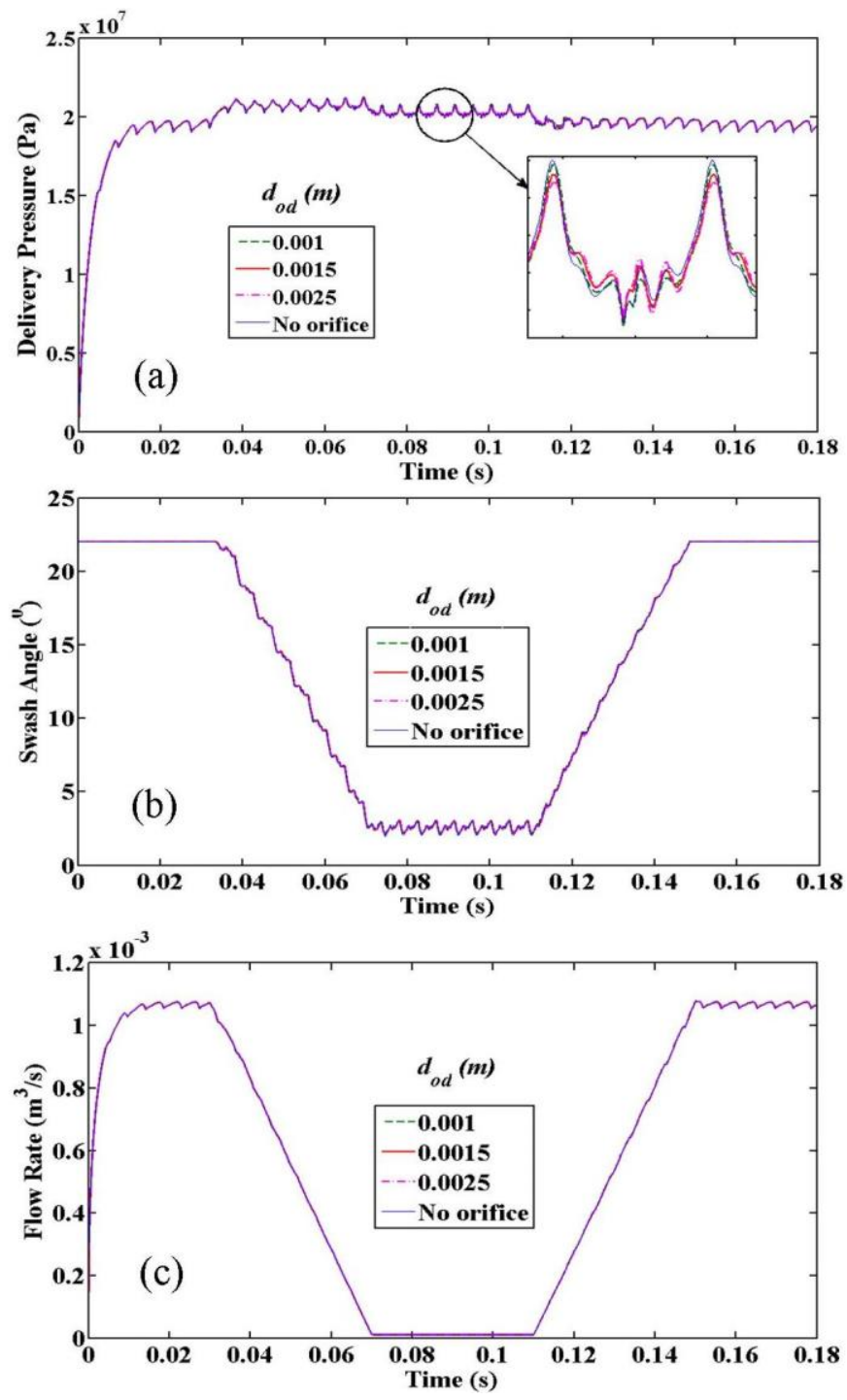

Fig. 7 Effect of entry orifice the spool valve

\subsection{Evaluation of the Size of Drain Side Orifice of the Spool Valve}

A similar study has been conducted by varying the drain orifice diameter from $1 \mathrm{~mm}$ to $3 \mathrm{~mm}$ in which Eqs. (8b) and (8c) have been invoked, while for no drain orifice case, Eq. (8c) has been used. Figure 8 illustrates the comparison of the performances in terms of delivery pressure, swash angle and delivery flow rate characteristics for load variation depicted in Fig. 5. The study reveals that direct drain connection between the spool end chamber and reservoir is the best option. Introduction of orifice creates back pressure due to which during increase in loading on the pump more amount of force was required to move the spool against the spring force. As a result the delivery pressure shoots up beyond the designed cut-off pressure, particularly for orifices of $1 \mathrm{~mm}$ and $2 \mathrm{~mm}$ sizes. For these orifices, the internal dynamics of the pump take longer time to stabilize the swash plate for near zero delivery flow rate due to full closure of the load orifice. Consequently, after withdrawal of the loading, it takes more time for the flow and 
delivery pressure to recover to the cut-in setting. Increasing the diameter of the orifice ( $3 \mathrm{~mm})$ close to the no orifice situation shows better performance of the pump. Therefore, it is suggested that no orifice may be used at the drain side of the valve. In absence of orifice, for the rest of the study, Eq. (8c) has been used as a model of drain flow rate.
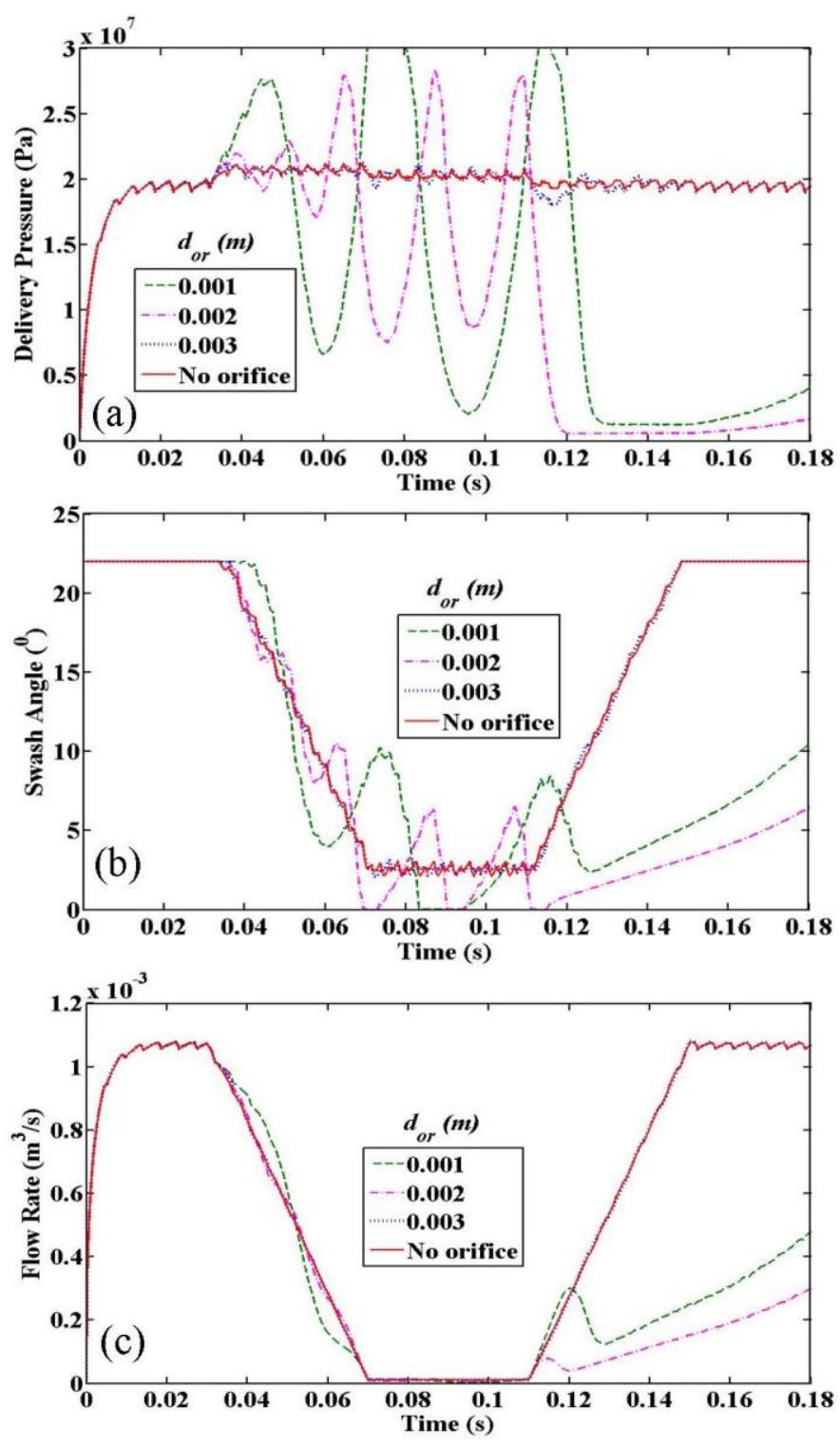

Fig. 8 Effect of drain side orifice of the spool valve

\subsection{Effect of Over-Lap and Under-Lap of the Spool Valve on the Pump Performance}

The lap condition of the central spool land has a great influence on the pump dynamics. In the studies conducted in the previous sections, the central spool land was considered to have overlap $o_{d}$ of $10 \mu \mathrm{m}$ at the left side and underlap $u_{r}$ of $90 \mu \mathrm{m}$ at the right side of it with respect to the metered port shown in Fig. 2. Now a set of lap combinations have 

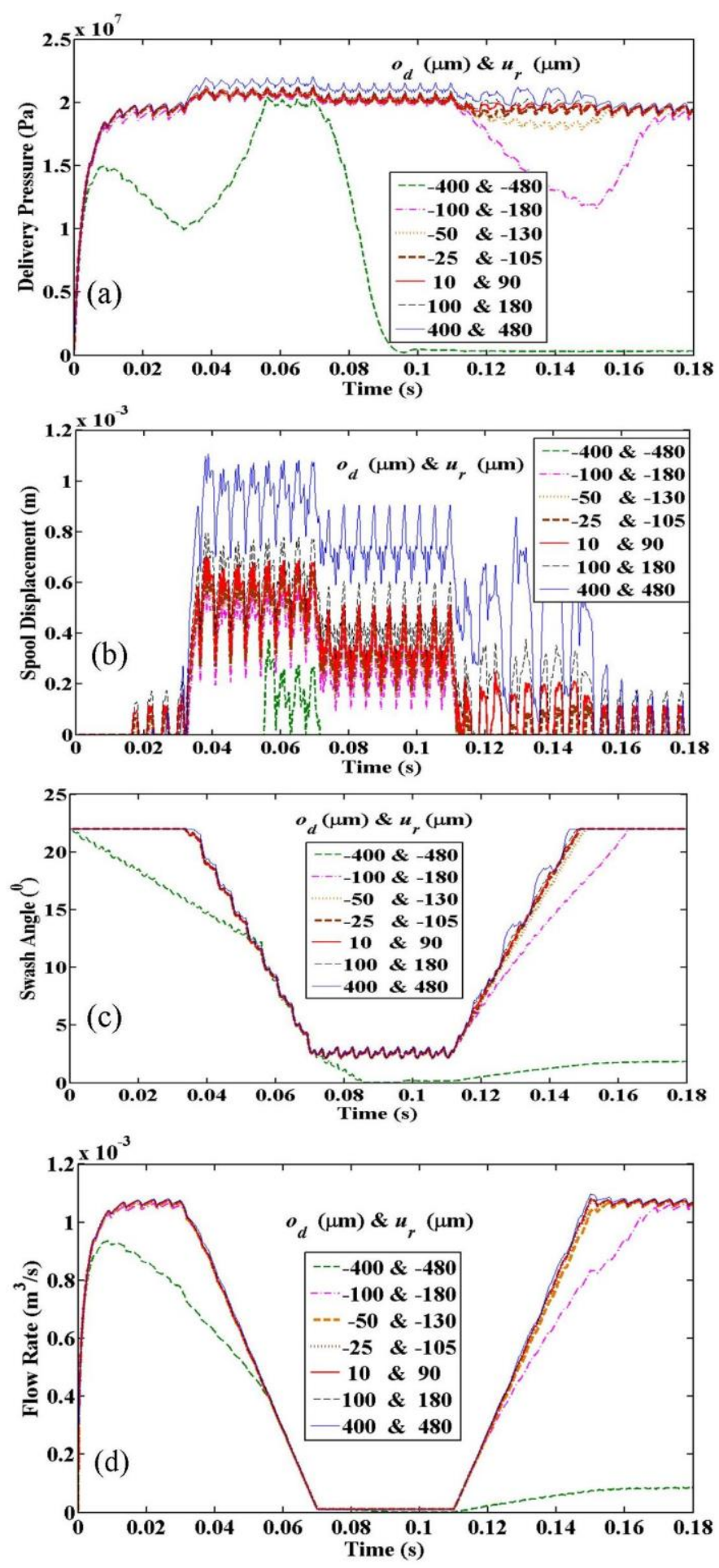

Fig. 9 Effect of over-lap and under-lap of the spool valve

been studied without altering the main configuration of the spool valve. In fact the study has been extended for reverse lap condition in which the central spool land is under 
lapped at left side and overlapped at right side. Figure 9 shows the result of the study, where both are denoted with negative signs. All the performance predictions have been made against same area pattern of load orifice shown in Fig. 5. It can be observed that within a range of the lap conditions of the spool valve, the performance of the pump remains satisfactory. The study also reveals that reversed lap condition in the order of $25 \mu \mathrm{m}$ underlap and $105 \mu \mathrm{m}$ overlap may be admissible. Up to the lap condition in the order of $100 \mu \mathrm{m}$ overlap and $180 \mu \mathrm{m}$ underlap, the pump operates within the designed cutin and cut-off condition. The degradation in the performance for larger reversed lap is due to the fact that at the beginning of the pump operation, the stroking cylinder is directly connected to the pump delivery line, which affects the cut-in pressure of the pump. On the other hand, for the larger overlap at the left side of the spool, the cut-off pressure is increased because more pressure force is required to overcome the overlap length. The corresponding dynamic characteristics of spool valve displacement, swash angle and flow rate of the pump are also shown in Fig. 9(c) and 9(d).

\subsection{Evaluation of the Size of Clearance Orifice}

As shown in Fig. 2, the additional orifice added between the spool valve and stroking cylinder plays an important role particularly during transition from cut-off to cut-in operating condition. It has a small influence on the cut-off pressure setting, but it is really important when the load valve comes back from its cut-off area setting to cut-in area setting and stays steadily within the cut-in area zone. This orifice acts as a bypass route of the pressurized fluid of stroking cylinder when the load of the pump is being reduced from cut-off to cut-in condition and even below that. The pre-compression of the spring of the spool valve causes closure of the metered port once the load is reduced. For depressurization of the stroking cylinder, the entrapped oil needs to be leaked to the case drain. The radial clearance and the underlap of the spool land may not be sufficient to provide the leakage necessary for the depressurization so that the swash plate can able to come back to its rated orientation. This is evident from Fig. 10, where the performance of the pump has been studied for different sizes of the clearance orifice starting from zero size orifice, equivalent to no orifice. The same loading pattern as shown in Fig. 5 has also been used for this study and apart from varying the diameter of the clearance orifice; all other parameters are kept at their nominal values. It can be seen that for a diameter of $750 \mu \mathrm{m}$, the recovery of cut-in pressure from cut-off pressure occurs in the pump in a smooth manner. The behaviours of swash angle and the delivery flow rate also have been found to satisfactory. Below this size of orifice, the return of the swash angle to its rated value gets delayed as can be observed from the figure thereby the delivery pressure and flow rate of the pump get affected. Orifice size of $1 \mathrm{~mm}$ has resulted higher pressure ripple due to oscillations in the swash dynamics. Therefore, from this study, the size of the clearance orifice has been recommended as $750 \mu \mathrm{m}$. The sizing of the spool valve obtained from dynamic simulation has been furnished in Table 5. 

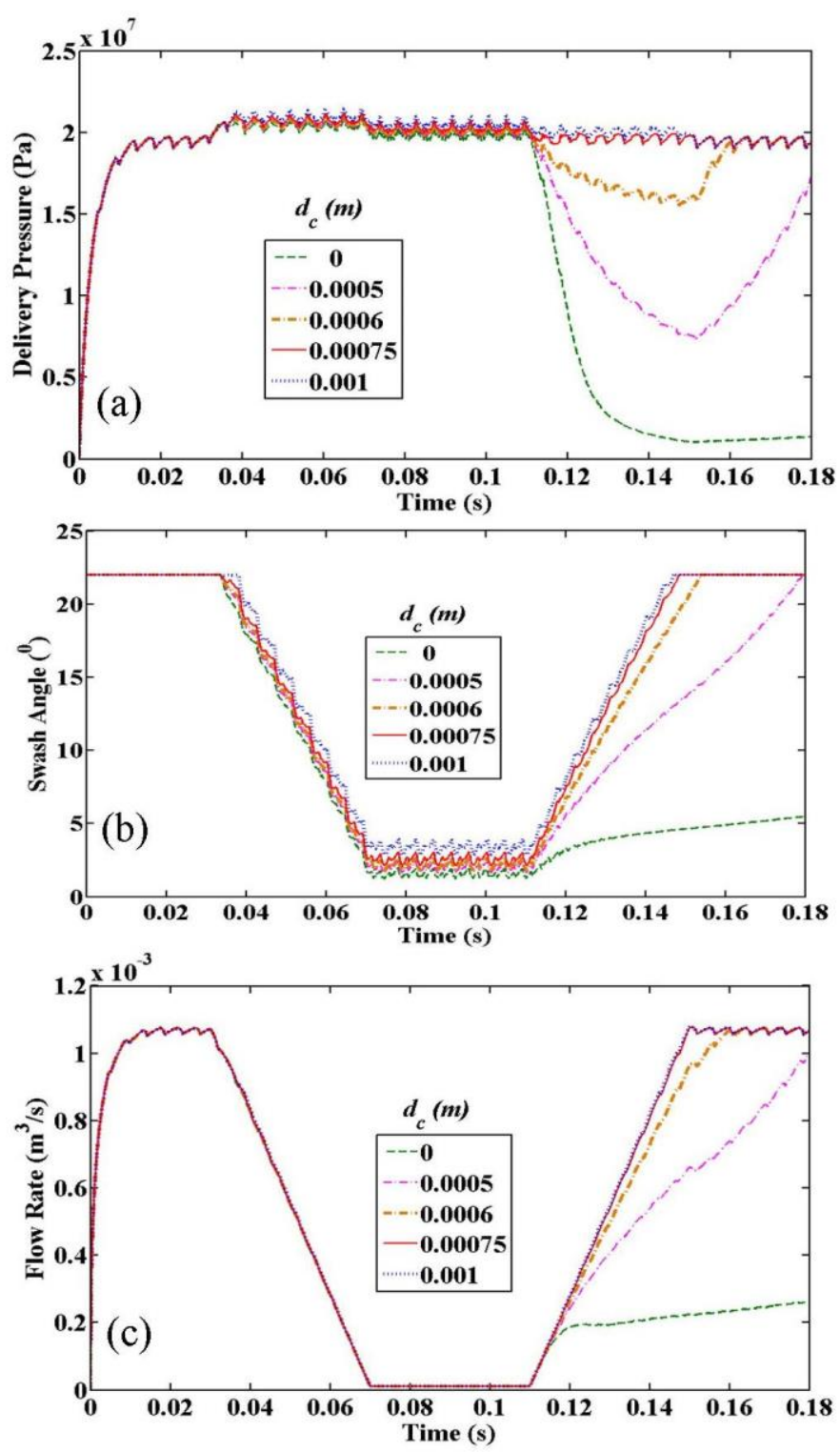

Fig. 10 Effect of clearance orifice of the spool valve

\section{PERFORMANCE ANALYSIS BETWEEN DOUBLE SPOOL COMPENSATOR WITH SINGLE SPOOL COMPENSATOR}

Figure 11 presents the comparison of the dynamic performance of the present pressure compensator with another one having a two stage spool valve developed in an earlier study [14]. In both the cases apart from the spool valves all other components of the pump remain same. The pump dynamics has been studied for the same load dynamics as shown in Fig. 5. It can be observed from Fig.11(a) that a pressure overshoot appears when the orifice goes from cut-in area to cut-off area in both types of pressure compensators. However peak overshoot is more in the case of the compensator with two stage spool valve. The primary reason behind this feature may be attributed to the 
combined effect of the two springs associated with the spool ends, although both the designs of pressure compensator maintain the same cut-in pressure but the cut-off pressure is high in case of compensator with double spool. Figure 11(b) illustrates that the pressure ripples in the rate cylinder at the valve transient region and the full load region is slightly more in case of single spool compensator design. The stroking cylinder pressure dynamics has been shown in the Fig.11(c). Figures 11(d) and 11(e) demonstrate the features of swash plate dynamics and the flow dynamics of the system. At the cut-off region, the flow is nearly zero for both the cases, but the swash angle is less in case of compensator with two stage spool valve than compensator with single stage spool valve.
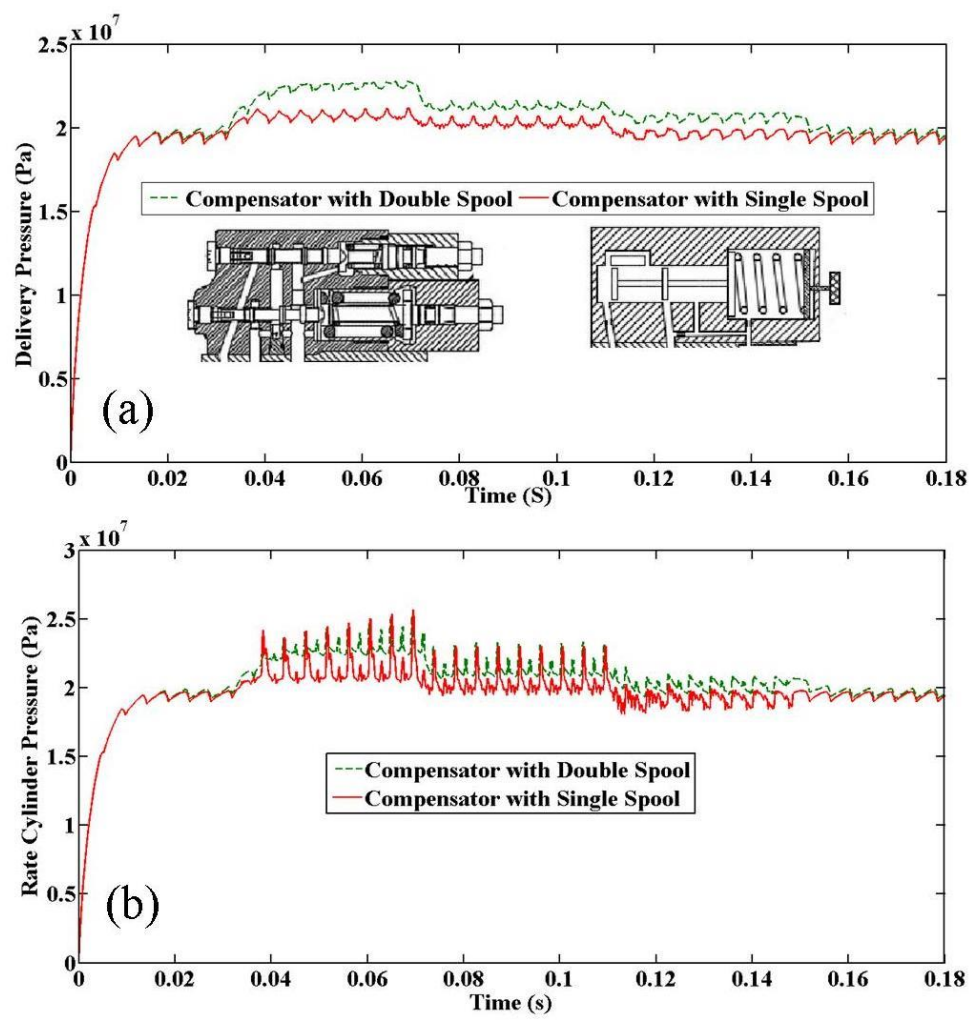

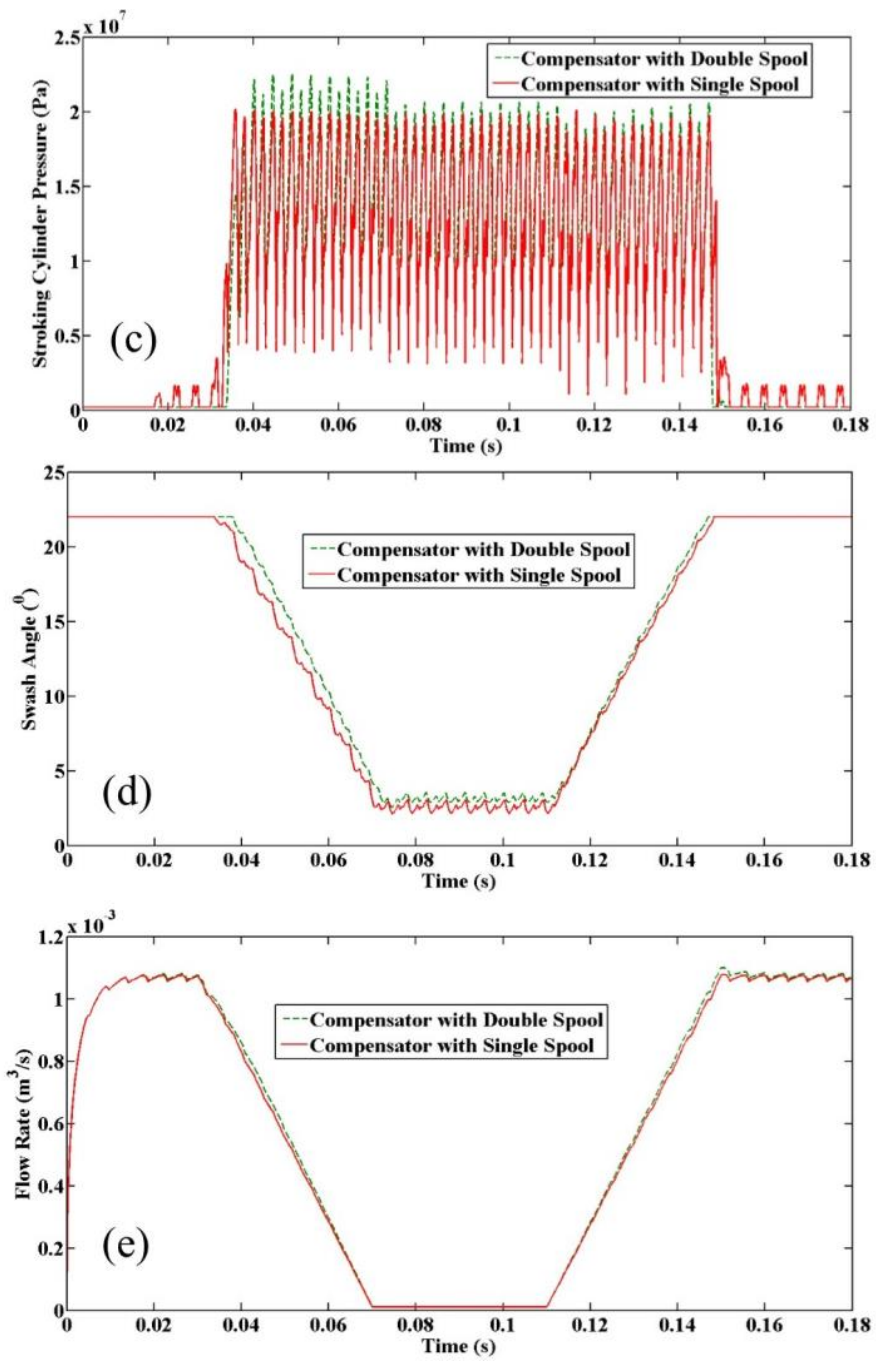

Fig. 11 Performance comparisons between two compensators

Table 5 Parameters obtained from dynamic simulation

\begin{tabular}{cccc}
\hline \hline Parameter & Value & Parameter & Value \\
\hline$d_{o d}$ & Not required & $u_{d}$ & $105 \mu \mathrm{m}$ to $180 \mu \mathrm{m}$ \\
$d_{o r}$ & Not required & $d_{c}$ & $0.75 \mathrm{~m}$ \\
$O_{d}$ & $-25 \mu \mathrm{m}$ to $100 \mu \mathrm{m}$ & & \\
\hline \hline
\end{tabular}

\section{PERFORMANCE COMPARISON WITH A REAL PUMP}

The objective of this section is to verify whether the simulated performance of the axial piston pump having the designed single spool compensator matches with a commercially available similar pump but having double spool compensator. In the earlier study made by Mondal et al. [14], the same experimental test setup had been used to verify the correctness of the simulation software and the design methodology. In Fig.12(a) the complete circuit has been shown with the symbolic representation of the components and 
sensors. A standard petroleum based hydraulic oil (HLP68) is used as working fluid. The pump has been driven by a three phase induction motor controlled by a variable frequency drive (VFD) as per requirement of the speed. The variable displacement swash plate type axial piston pump and two cylinders, rate and stroking are housed in a single casing. The spool valve is fitted on the pump casing. Some components like filter and proportional valve are connected in series, while the pressure relief valve and pressure transducer are connected in parallel to the circuit. A proportional solenoid operated direction as well as flow control valve PV with an integrated control electronics ICE module mounted on it, has been used as the load orifice. The system is operated via an algorithm developed on the LabVIEW (version 2013) environment installed on the HOST PC. The algorithm generates a continuous voltage which is fed to the PV via the output module OM (NI 9263) of the NI-cRIO 9081 real time system RTS. The pump pressure is measured corresponding to this voltage feed via the pressure transducer PT. The analog signals from the PT are relayed back to the HOST PC for purposes of storage and analysis via the input module IM of the RTS.A photographic view of the setup with different components has been shown in Fig. 12(b), while the details of the hydraulic and electrical components have been given in Table 6 .

The pressure compensator model which consists of a single stage spool valve has been verified with the experimental result and simulation of system with two stage spool valve subjected to same loading pattern. The loading has been obtained by varying the command signal to the PV as shown in Fig. 13(a). Figure 13(b) shows the performance comparison result in terms of the delivery pressure characteristics against the loading pattern. The spring pre-compression setting of the single spool valve has been adjusted to $0.0072 \mathrm{~m}$ to have a satisfactory matching with the experimental one. In case of compensator with double spool, the spring pre-compression setting of the bottom spool is kept fixed at $0.00415 \mathrm{~m}$, while that for the top spool is set at $0.0086 \mathrm{~m}$ to match with the experimental result as shown in Fig.13(a). It may be mentioned that although the compensator design with single spool valve has been performed for $20 \mathrm{MPa}$ cut-off pressure, it has been set as $18.5 \mathrm{MPa}$ for the verification study to maintain consistency with a factory set cut-off value of the real pump. 


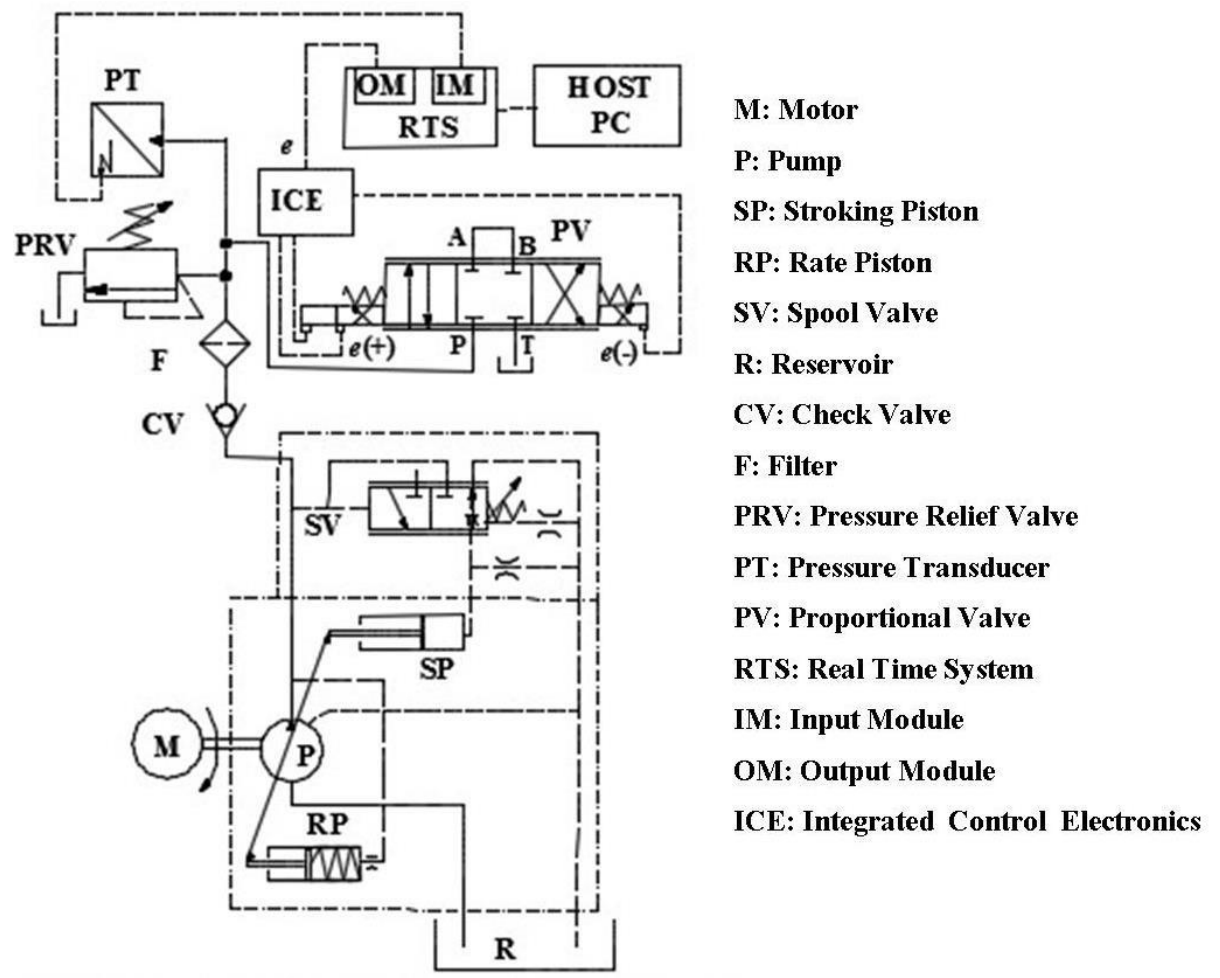

Fig. 12 Experimental circuit diagram

Table 6 Details of the set-up components

\begin{tabular}{|c|c|}
\hline Component (make) & Specifications \\
\hline Motor, $\mathbf{M}(\mathrm{ABB})$ & 3-phase; $37 \mathrm{KW} ; 2945 \mathrm{rpm}$; \\
\hline $\begin{array}{l}\text { Variable Frequency Drive, VFD } \\
\text { (ABB) }\end{array}$ & $30 \mathrm{~kW}$ \\
\hline Pump,P(Rexroth) & A10VSO 45DR/31; \\
\hline Pressure Transducer, PT (Kistler) & 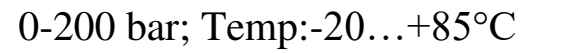 \\
\hline Filter, $\mathbf{F}$ (Stauff) & $\begin{array}{l}\text { Maximum Working pressure } 350 \\
\text { bar }\end{array}$ \\
\hline Proportional valve, PV (Rexroth) & $\begin{array}{l}\text { 4WREE series;50 lpm at } 10 \mathrm{bar} \\
\text { drop }\end{array}$ \\
\hline Hose Pipe (Parker) & 250 bar; $16 \mathrm{~mm}(5 / 8 " \mathrm{BSP})$ \\
\hline $\begin{array}{l}\text { Pressure Relief valve, } \\
\text { PRV(Yuken) }\end{array}$ & EBG-03-H-11; 210bar \\
\hline $\begin{array}{l}\text { Real-time system, RTS(NI } \\
\text { systems) }\end{array}$ & 1GHz, 32-bit NI-cRIO 9081 \\
\hline Input module, IM (NI systems) & \pm 10 VA/D NI-cRIO 9215 \\
\hline Output module, OM (NI systems) & $\pm 10 \mathrm{~V}$ D/A NI-cRIO 9263 \\
\hline
\end{tabular}



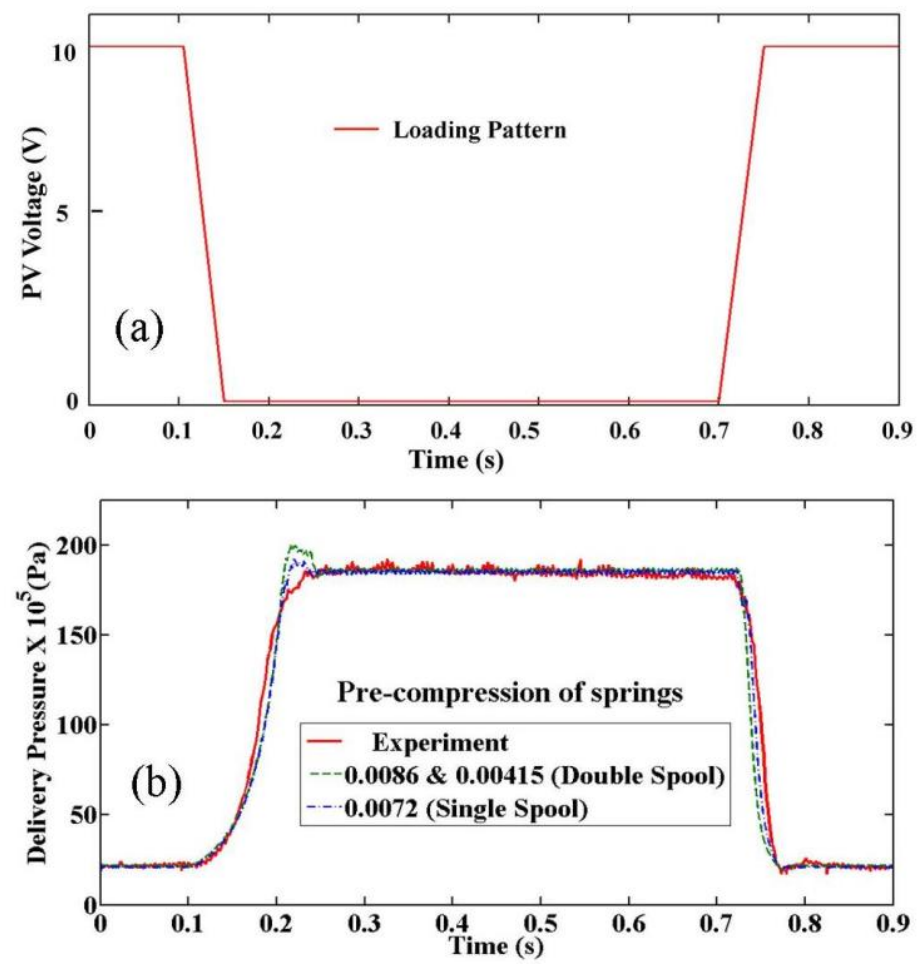

Fig. 13 Experimental and simulation validation for a load variation

\section{Conclusion}

In this present work, a simplified spool valve instead of a two stage spool valve has been incorporated in the pressure compensator of a variable displacement axial piston pump in order to perform a comparative study with a commercial pump. The design sensitivity of the spool valve has been carried out through simulation to identify the critical size of the parameters, which affects the pump performance. The study suggests no orifice at the entry of the spool valve and direct drain connection between the spool end chamber and reservoir. In particular, it has been found that introduction of drain orifice creates back pressure due to which during increase in loading on the pump more amount of force was required to move the spool against the spring force. It has been observed from the sensitivity analysis that within a range of lap conditions of the spool valve, the performance of the pump remains satisfactory. In fact the study has revealed that reversed lap condition in the order of $25 \mu \mathrm{m}$ underlap and $105 \mu \mathrm{m}$ overlap may be admissible. The role of clearance orifice has been revealed to act as a bypass route of the pressurized fluid of stroking cylinder when the load of the pump is being reduced from cut-off to cut-in condition and even below that. The size of the clearance orifice has been recommended as $750 \mu \mathrm{m}$. From the theoretical performance comparison between single stage and two stage spool valve, it has been found that although both the designs of pressure compensator maintain the same cut-in pressure, but the cut-off pressure is high in case of compensator with double spool. By systematic design, it is possible to have a single stage spool valve controlled pressure compensator that can produce performance of the variable displacement axial piston pump at par with a similar commercially available pump. 


\section{Declarations}

Availability of data and materials

Not applicable.

\section{Competing interests}

The authors declare no competing financial interests.

\section{Funding}

Support from Extramural Research and Intellectual Property Rights [grant number 1431] and Aeronautical Research and Development Board [grant number 1669] both under DRDO, India for the development of the experimental setup and the scholarship support from the latter organization.

\section{Authors' contributions}

$\mathrm{NM}$ and RS contributed the theoretical, experimental work, including the built of experimental set-up and wrote the paper. DS contributed by revising the paper and took the charge of whole arrangement. All authors read and approved the final manuscript.

\section{Acknowledgement}

The authors acknowledge the support provided by Mr. Shouvik Chaudhuri from Mechanical systems and Control Laboratory of Jadavpur University to conduct the experiment.

\section{Reference}

[1] Norhirni MZ, Hamdi M, Nurmaya Musa S, Saw LH, Mardi NA and Hilman N (2011) Load and stress analysis for the swash plate of an axial piston pump/motor. Journal of dynamic systems, measurement, and control 133(6).

[2] Richardson D, Sadeghi F, Rateick Jr RG and Rowan S (2017) Experimental and analytical investigation of floating valve plate motion in an axial piston pump. Tribology Transactions 60(3): pp.537-547.

[3] Daher N and Ivantysynova M (2014) Energy analysis of an original steering technology that saves fuel and boosts efficiency. Energy Conversion and Management 86: pp.1059-1068.

[4] Ye, S. G., Zhang, J. H., \& Xu, B. (2018) Noise reduction of an axial piston pump by valve plate optimization. Chinese Journal of Mechanical Engineering, 31(1), 116.

[5] Wang S (2013) Novel Piston Pressure Carryover for Dynamic Analysis and Designs of the Axial Piston Pump. ASME Journal of Dynamic Systems, Measurement, and Control 135(6): 024504-1-7.

[6] Zhao, B., Guo, W., \& Quan, L. (2020) Cavitation of a Submerged Jet at the Spherical Valve Plate/Cylinder Block Interface for Axial Piston Pump. Chinese Journal of Mechanical Engineering, 33(1), 1-15.

[7] Wang S (2012) Improving the volumetric efficiency of the axial piston pump. ASME Journal of Mechanical Design 134(11): 111001-111001-7. 
[8] Zheng N, Tong B, Yang W and Zhang G (2020) Study on pressure balance and clearance flow characteristics of composite-grooved piston-copper pair. Journal of the Brazilian Society of Mechanical Sciences and Engineering 42: pp.1-11.

[9] Kemmetmüller W, Fuchshumer F and Kugi A (2010) Nonlinear pressure control of self-supplied variable displacement axial piston pumps. Control Engineering Practice 18(1): pp.84-93.

[10] Wei J, Guo K, Fang J, and Tian Q (2015) Nonlinear supply pressure control for a variable displacement axial piston pump. Proceedings of the Institution of Mechanical Engineers, Part I: Journal of Systems and Control Engineering 229(7): pp.614-624.

[11] Kaliafetis P and Costopoulos T (1995) Modelling and simulation of an axial piston variable displacement pump with pressure control. Mechanism and Machine Theory 30(4): pp.599-612.

[12] Zhou, J., Zhou, J., \& Jing, C. (2020). Experimental Research on the Dynamic Lubricating Performance of Slipper/Swash Plate Interface in Axial Piston Pumps. Chinese Journal of Mechanical Engineering, 33(1), 1-7.

[13] Manring ND, Mehta VS, Nelson BE, Graf KJ and Kuehn JL (2013) Increasing the power density for axial-piston swash-plate type hydrostatic machines. ASME Journal of Mechanical Design 135(7): 071002-071002-6.

[14] Mondal N, Saha R, Mookherjee S and Sanyal D (2019) A novel method to design pressure compensator for variable displacement axial piston pump. Proceedings of the Institution of Mechanical Engineers, Part E: Journal of Process Mechanical Engineering 233(2): pp.314-34.

[15] Maiti R and Narayan P (2011) An experimental investigation on swash plate control torque of a pressure compensated variable displacement inline piston pump. In Proceedings of the 8th JFPS (Japan Fluid Power System Society) International Symposium on Fluid Power.

[16] Mandal NP, Saha R, Mookherjee S and Sanyal D (2014) Pressure compensator design for a swash plate axial piston pump. ASME Journal of Dynamic Systems, Measurement, and Control 136(2): 021001-021001-12.

[17] Rexroth Bosch Group, - Industrial Hydraulics Catalogue. Variable Axial Piston Pump, Type - A10VSO, series-31/DR, RA92711, http://www.pneumax.co.th/catalogue/hyd/rexroth/ pump/ A10VSO. pdf /, 2004, accessed Sep20, 2020.

[18] Bhandari VB (2011) Design of machine elements. 2nd ed, Tata McGraw-Hill Education: pp. 395.

[19] Merrit HE (1967) Hydraulic control systems. 1st ed. John Wiley \& Sons, Inc., NewYork-London-Sydney.

[20] Özmen, Ö., Sinanoğlu, C., Caliskan, A., \& Badem, H. (2020). Prediction of Leakage from an Axial Piston Pump Slipper with Circular Dimples Using Deep Neural Networks. Chinese Journal of Mechanical Engineering, 33, 1-11.

[21] Ivantysyn J. and Ivantysynova M (2001) Physical fundamentals. In: Hydrostatics pumps and motors. 1st ed., Akademia Books International, New Delhi, India: pp. 32-33.

[22] Massey BS and Ward-Smith J (2006) Mechanics of fluids. $8^{\text {th }}$ ed., Taylor \& Francis, New York: pp.201-205. 
[23] Mandal NP, Saha R and Sanyal D (2012) Effects of flow inertia modelling and valve-plate geometry on swash-plate axial-piston pump performance. Proceedings of the Institution of Mechanical Engineers, Part I: Journal of Systems and Control Engineering: 226(4), pp.451-465.

[24] Bin, Z., Bing, X., Chunlin, X., \& Huayong, Y. (2009). Modeling and Simulation on Axial Piston Pump Based on Virtual Prototype Technology [J]. Chinese Journal of Mechanical Engineering, 22(1), 84-90.

\section{Nomenclature}

$A_{L} \quad$ load orifice area, $\mathrm{m}^{2}$

$c_{d}, c_{v} \quad$ discharge and velocity coefficient respectively

$c_{r c}, c_{s c}, c_{b c} \quad$ radial clearances between rate piston and cylinder, stroking piston and cylinder and barrel piston and cylinder respectively, $\mu \mathrm{m}$

$d_{d}, d_{r p}, d_{s p}$ diameters of the passageway through barrel piston, rate/bias piston and stroking/control piston respectively, $\mathrm{m}$

$d_{p} \quad$ barrel piston diameter, $\mathrm{m}$

$d_{s}, d_{s r} \quad$ spool land and modified spool land diameters, $\mathrm{m}$

$I_{s}$

$k_{r}$ mass moment of inertia of cradle and its lever, $\mathrm{kg}-\mathrm{m}^{2}$

rate cylinder spring stiffness, $\mathrm{N} / \mathrm{m}$

$k_{s}$ Stiffness of spool valve spring $\mathrm{N} / \mathrm{m}$

$l_{b}$

$l_{r t}, l_{s t}$

$m_{r}, m_{s}$

$m_{p}, m_{s v}$ length of the orifice inside the each barrel piston, $\mathrm{m}$

distances from barrel axis to rate cylinder and stroking cylinder axes, $\mathrm{m}$ masses of rate piston and stroking piston respectively, $\mathrm{kg}$ masses of barrel piston and spool respectively, $\mathrm{kg}$

$n$ number of barrel pistons

$P_{r c}, P_{s c}$ pressures inside the rate cylinder and stroking cylinder respectively, $\mathrm{Pa}$

$P_{d}, P_{r}, P_{s}$

$P_{d c i}, P_{d c o}$

$P_{p i}$

$Q_{L}$

$Q_{s c}$

$Q_{r c}$ delivery port, reservoir and suction port pressures respectively, $\mathrm{Pa}$ cut-in and cut-off pressures of the pump respectively, $\mathrm{Pa}$ pressure inside $i^{\text {th }}$ piston chamber, $\mathrm{Pa}$ flow rate through load orifice, $\mathrm{m}^{3} / \mathrm{s}$ flow rate from the spool valve to stroking cylinder, $\mathrm{m}^{3} / \mathrm{s}$ flow rate through the feedback orifice to the rate cylinder, $\mathrm{m}^{3} / \mathrm{s}$

$Q_{l r c} \quad$ leakage flow rate through the radial clearance between the rate piston and cylinder, $\mathrm{m}^{3} / \mathrm{s}$

$Q_{l s c} \quad$ leakage flow rate through the radial clearance between the stroking piston and cylinder, $\mathrm{m}^{3} / \mathrm{s}$

$Q_{l k i} \quad$ leakage flow rate through the radial clearance between the barrel piston and cylinder, $\mathrm{m}^{3} / \mathrm{s}$

$Q_{l c i} \quad$ leakage flow rate through the clearance between slipper pad and swash plate, $\mathrm{m}^{3} / \mathrm{s}$ 


$\begin{array}{ll}R_{p} & \text { pitch circle radius of piston on barrel, } \mathrm{m} \\ V_{p d}, V_{p s} & \begin{array}{l}\text { volumes between delivery port and load valve and between tank and suction port } \\ \text { respectively, } \mathrm{m}^{3}\end{array} \\ x_{r}, x_{s} & \begin{array}{l}\text { displacements of rate piston and stroking piston respectively, } \mathrm{m} \\ x_{p i}\end{array} \\ \delta_{0} & \text { displacement of } i^{\text {th }} \text { barrel piston from TDC, } \mathrm{m} \\ \delta_{s 0} & \text { pre-compressions of rate spring, } \mathrm{m} \\ \beta & \text { pre-compressions of spool spring, } \mathrm{m} \\ \mu & \text { bulk modulus of the hydraulic oil, } \mathrm{Pa} \\ \rho & \text { viscosity of the hydraulic oil, } \mathrm{Pa}-\mathrm{s} \\ \lambda & \text { density of the hydraulic oil, } \mathrm{kg} / \mathrm{m}^{3} \\ \omega & \text { swash angle, rad }\end{array}$



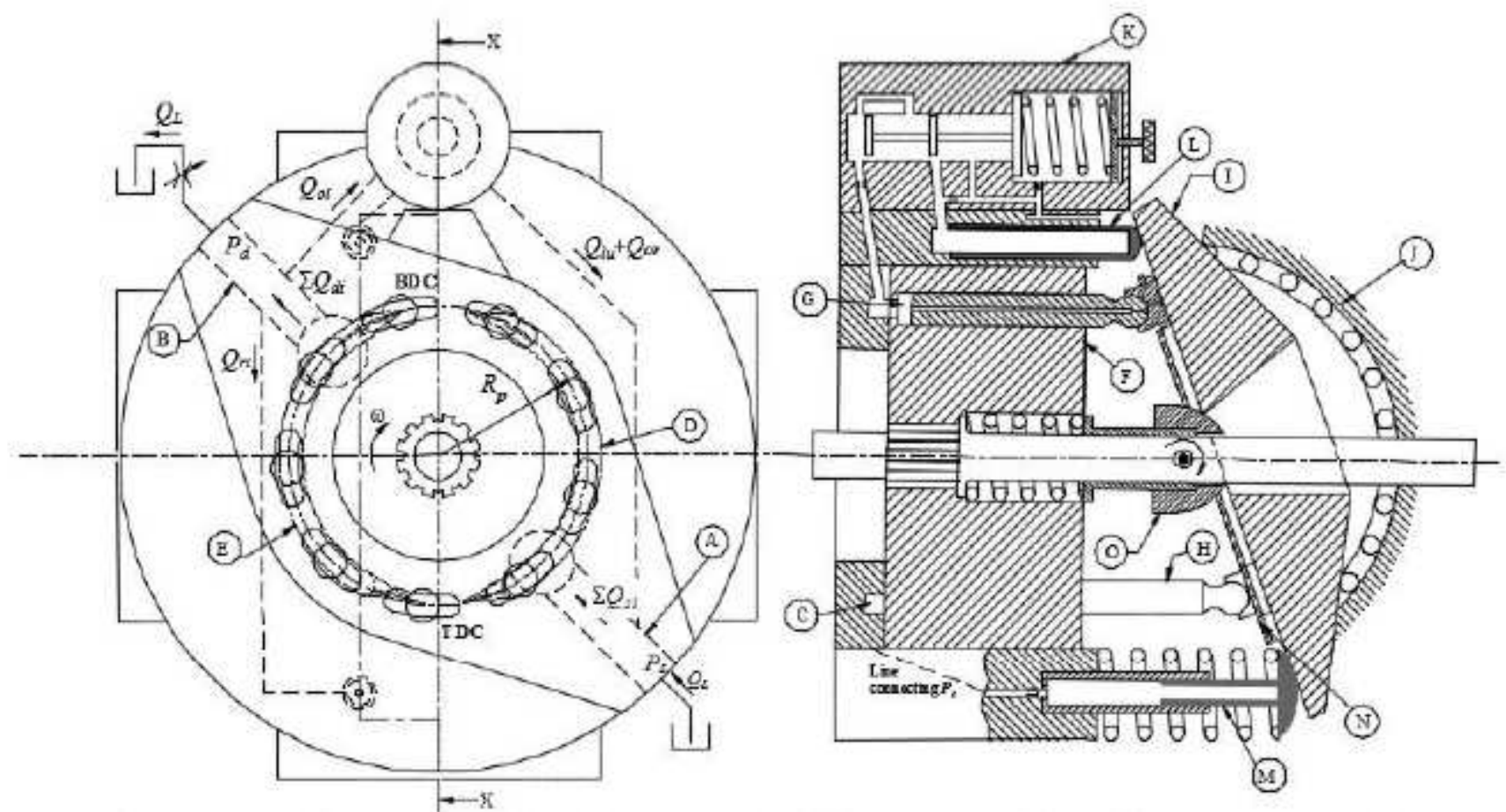

A-Suction Port B: Delivery Port C: Valve Plate D-Suction Kidney Port E:Delivery Kidney Port F: Barrel G: Barrel Bore $\mathrm{H}$ : Barrel Piston I. Swash Plate J: Bearing K: Spool Valve L: Stroking Piston M: Rate Piston NRetainer O: Bush

\section{Figure 1}

Schematic of a swash-plate axial piston pump with pressure compensator

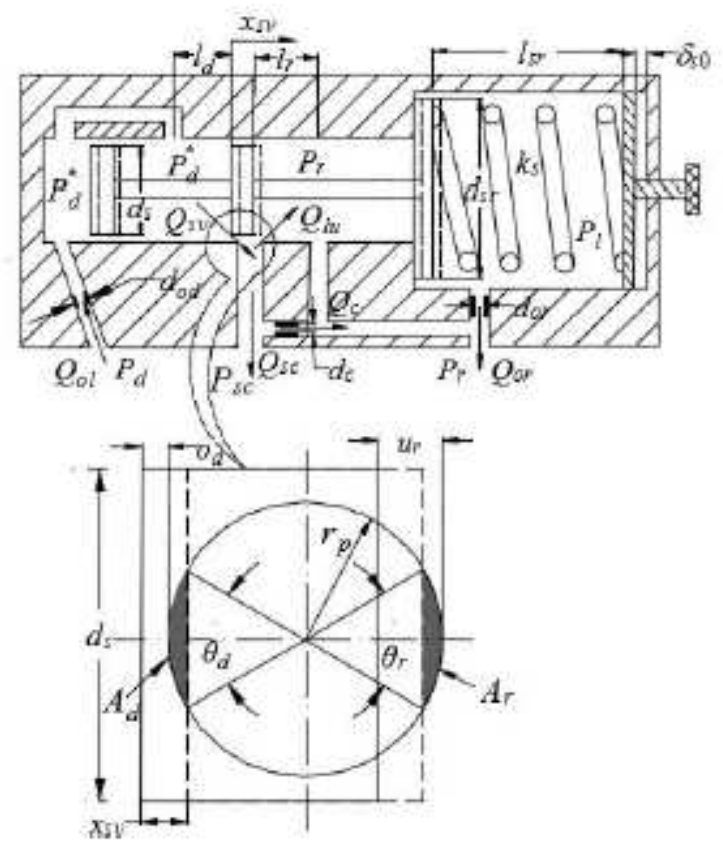

Figure 2 
Schematic of the single-stage control spool valve

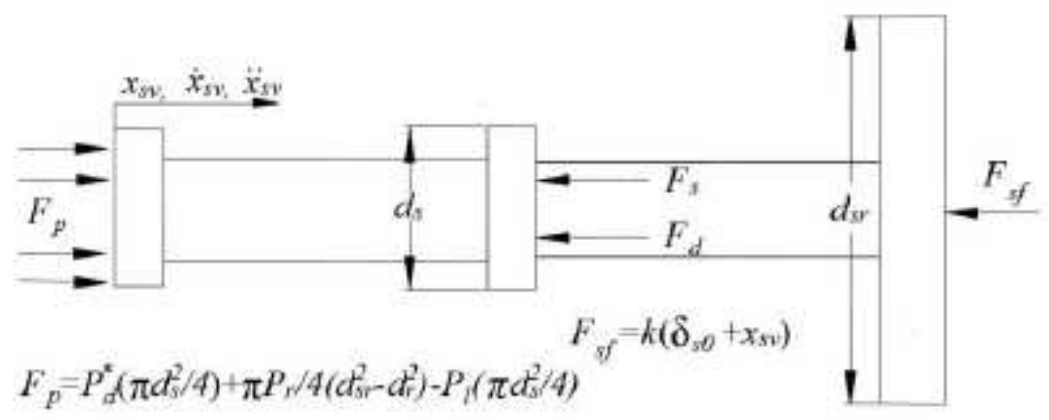

Figure 3

Free body diagram of the spool

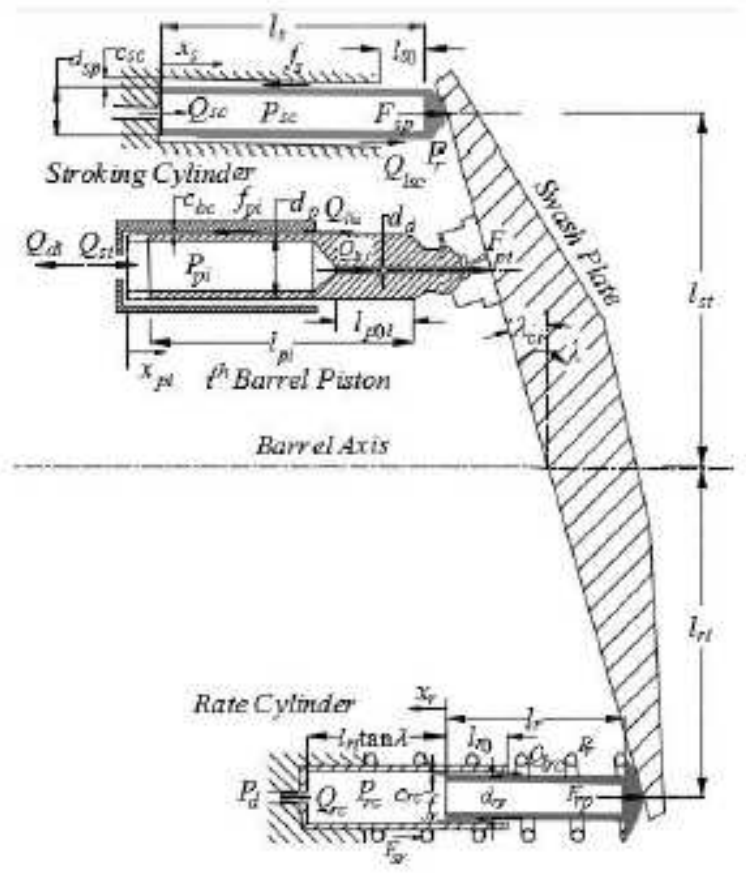

\section{Figure 4}

Cylinders position against swash plate

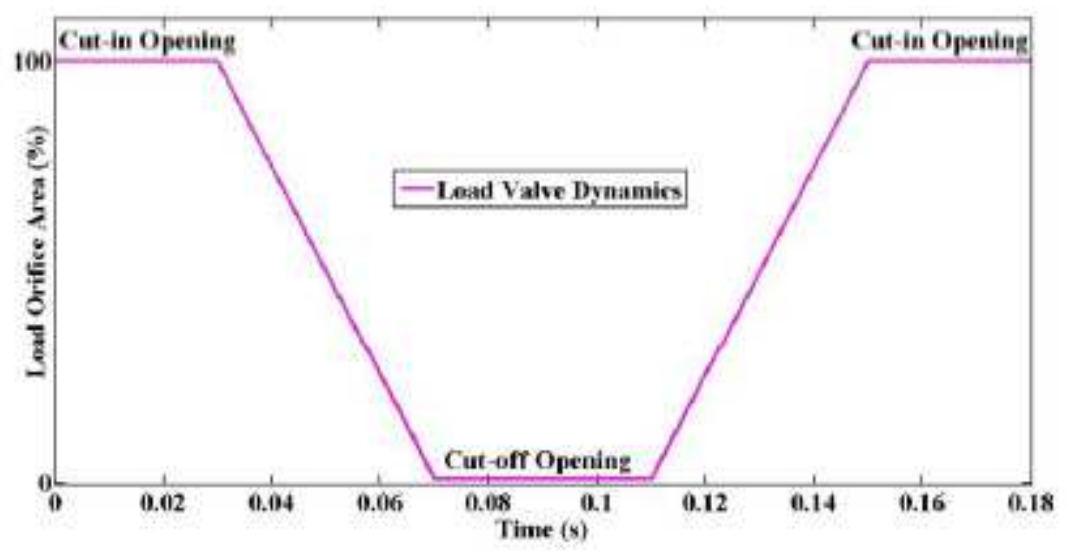


Figure 5

Loading pattern to the axial piston pump by changing orifice area
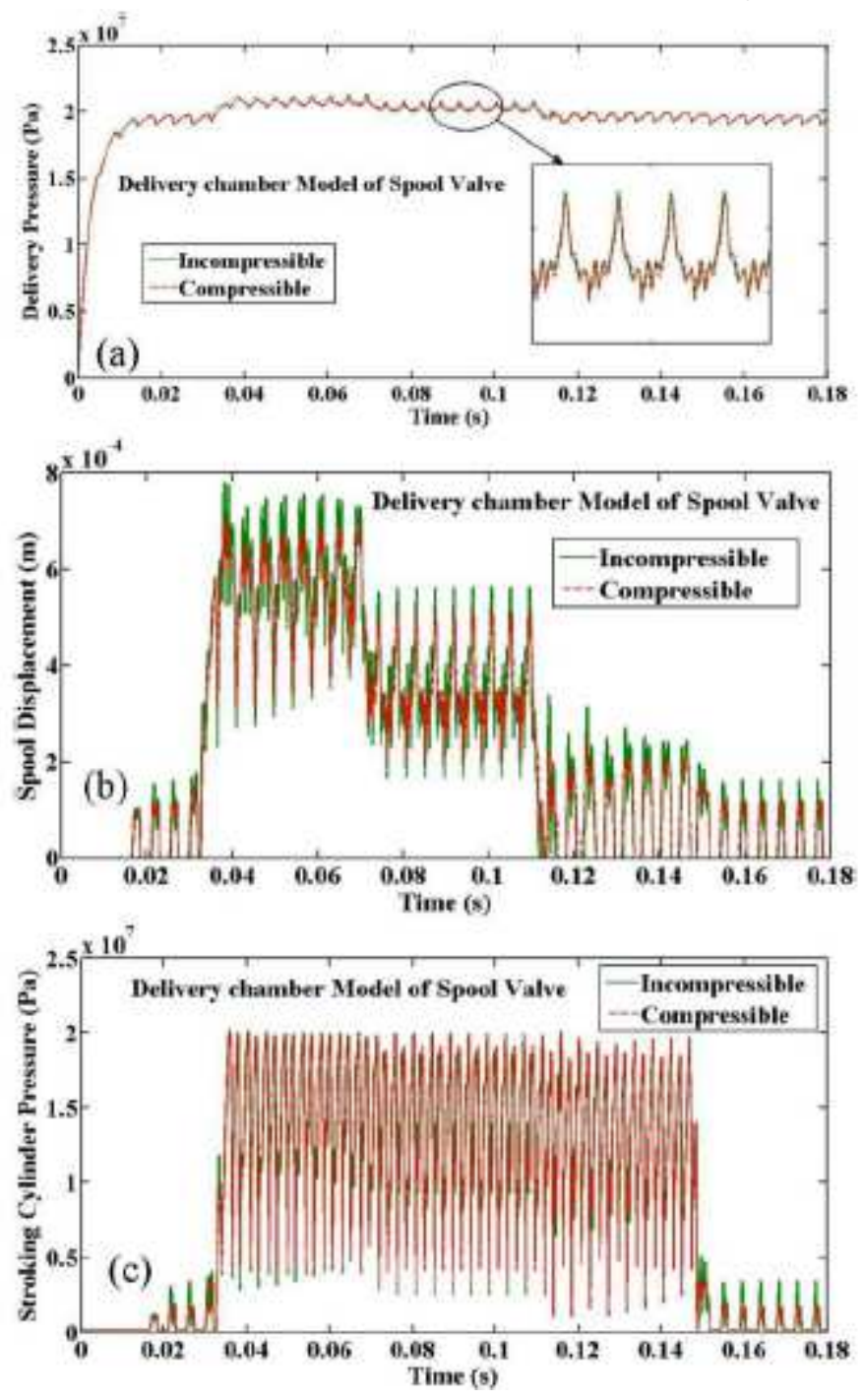

Figure 6

Effect of compressible model in the extreme left chamber of the spool valve 

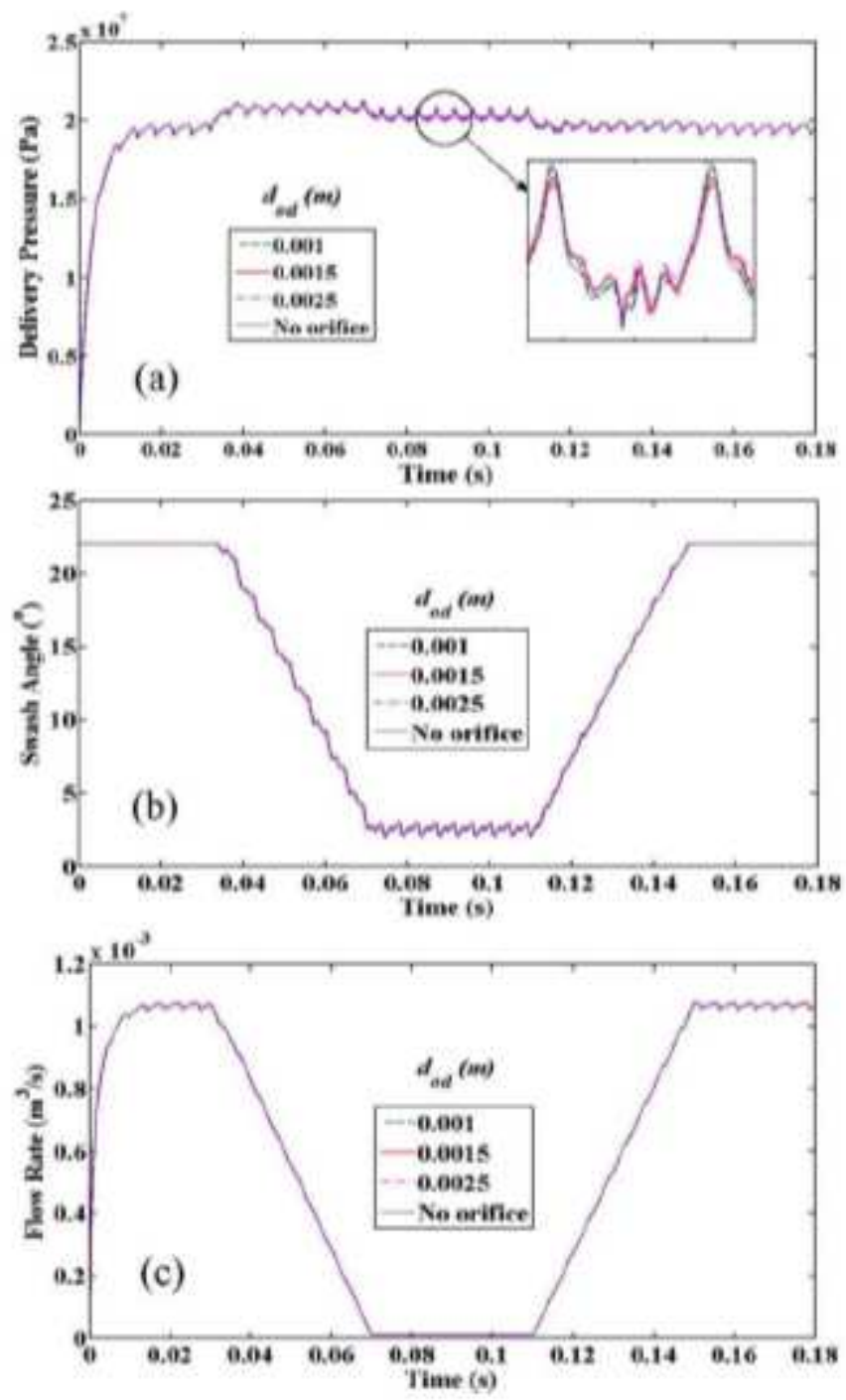

Figure 7

Effect of entry orifice the spool valve 

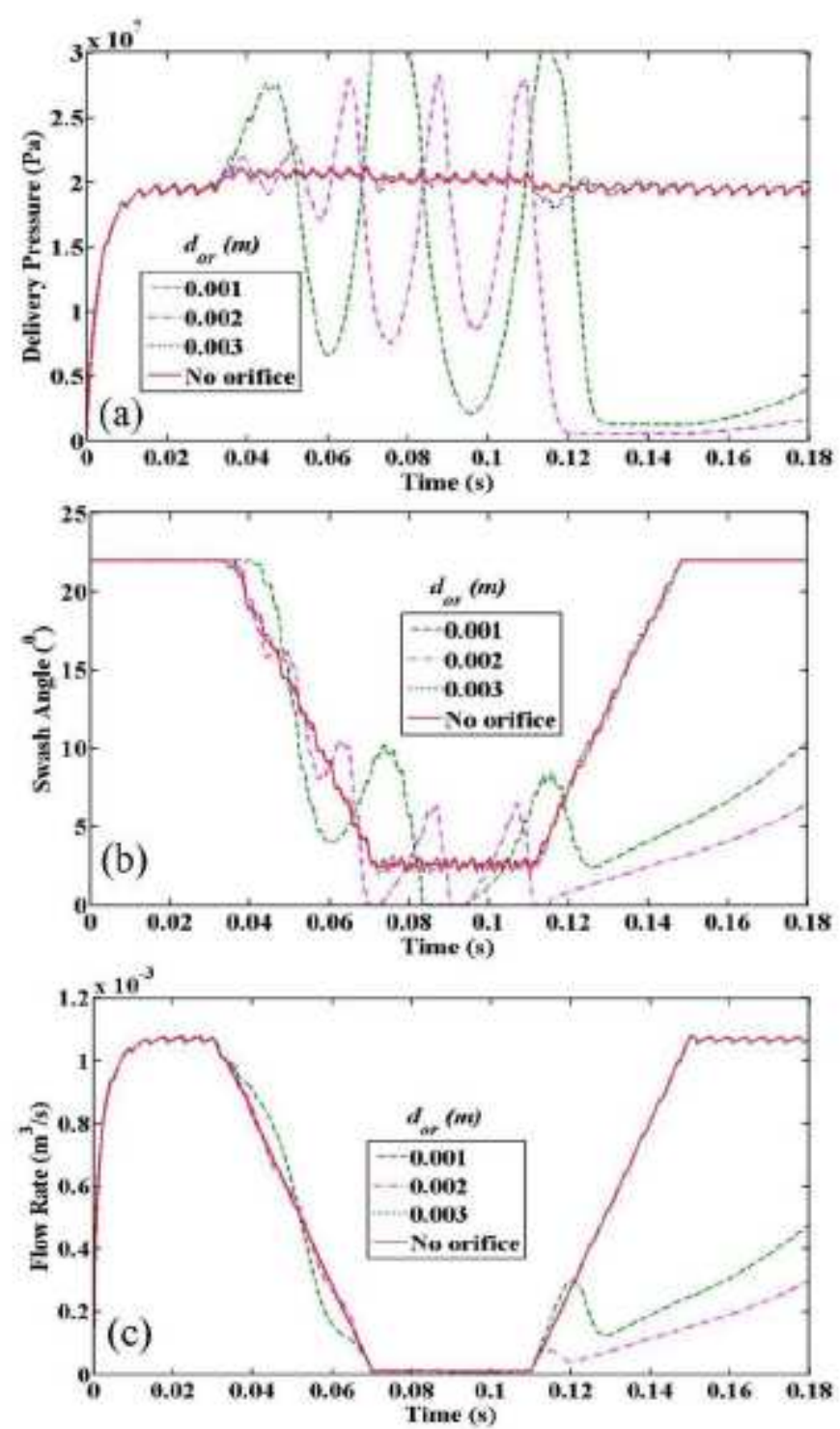

Figure 8

Effect of drain side orifice of the spool valve 

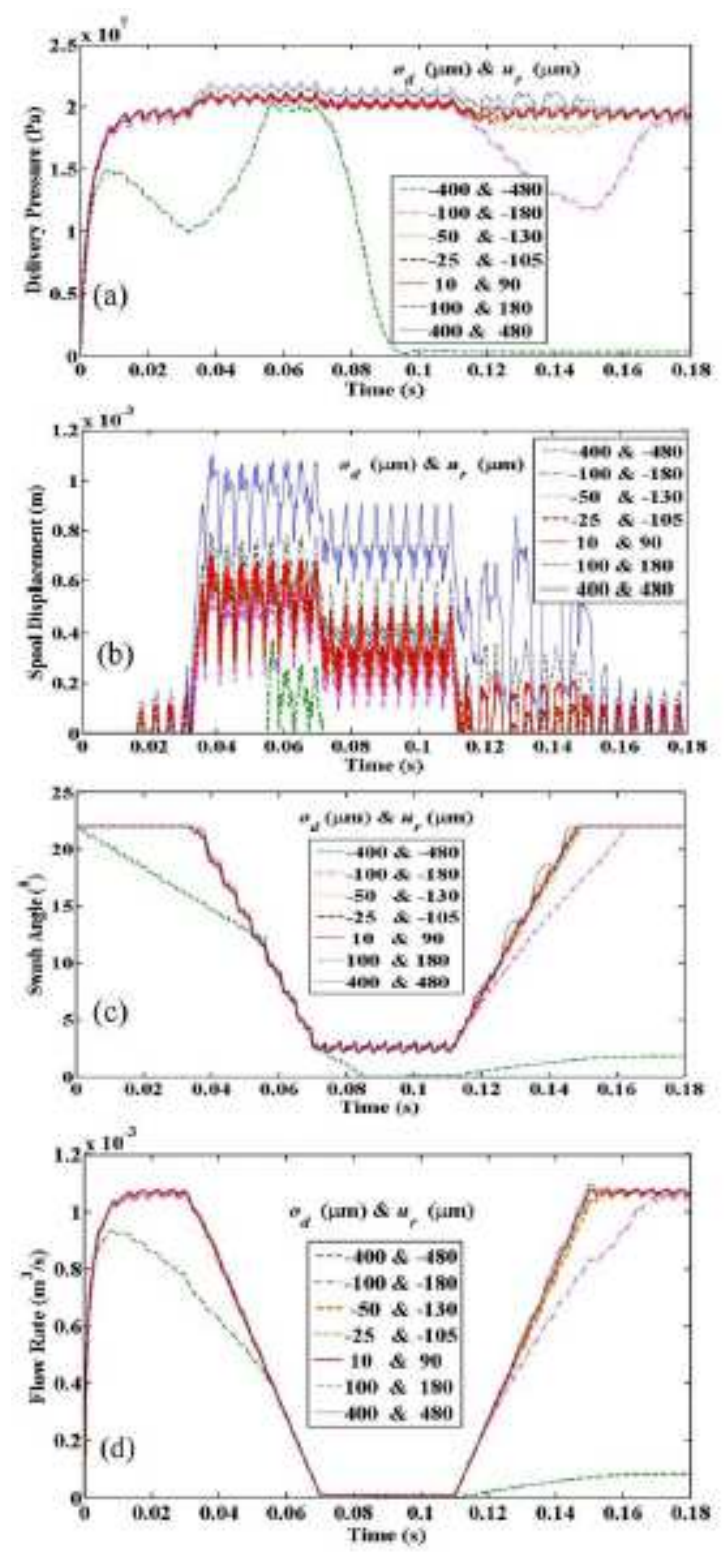

Figure 9

Effect of over-lap and under-lap of the spool valve 

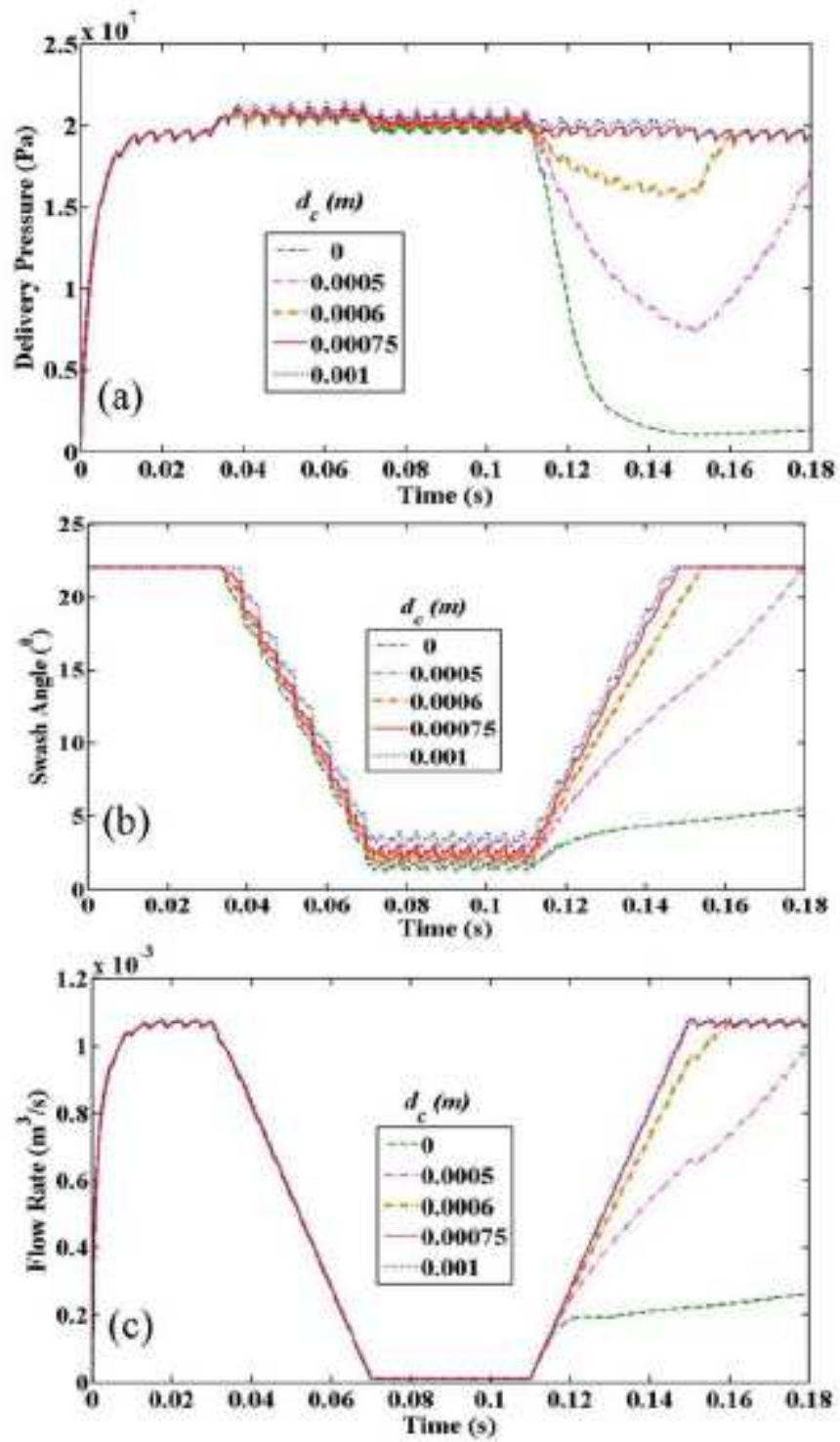

Figure 10

Effect of clearance orifice of the spool valve 

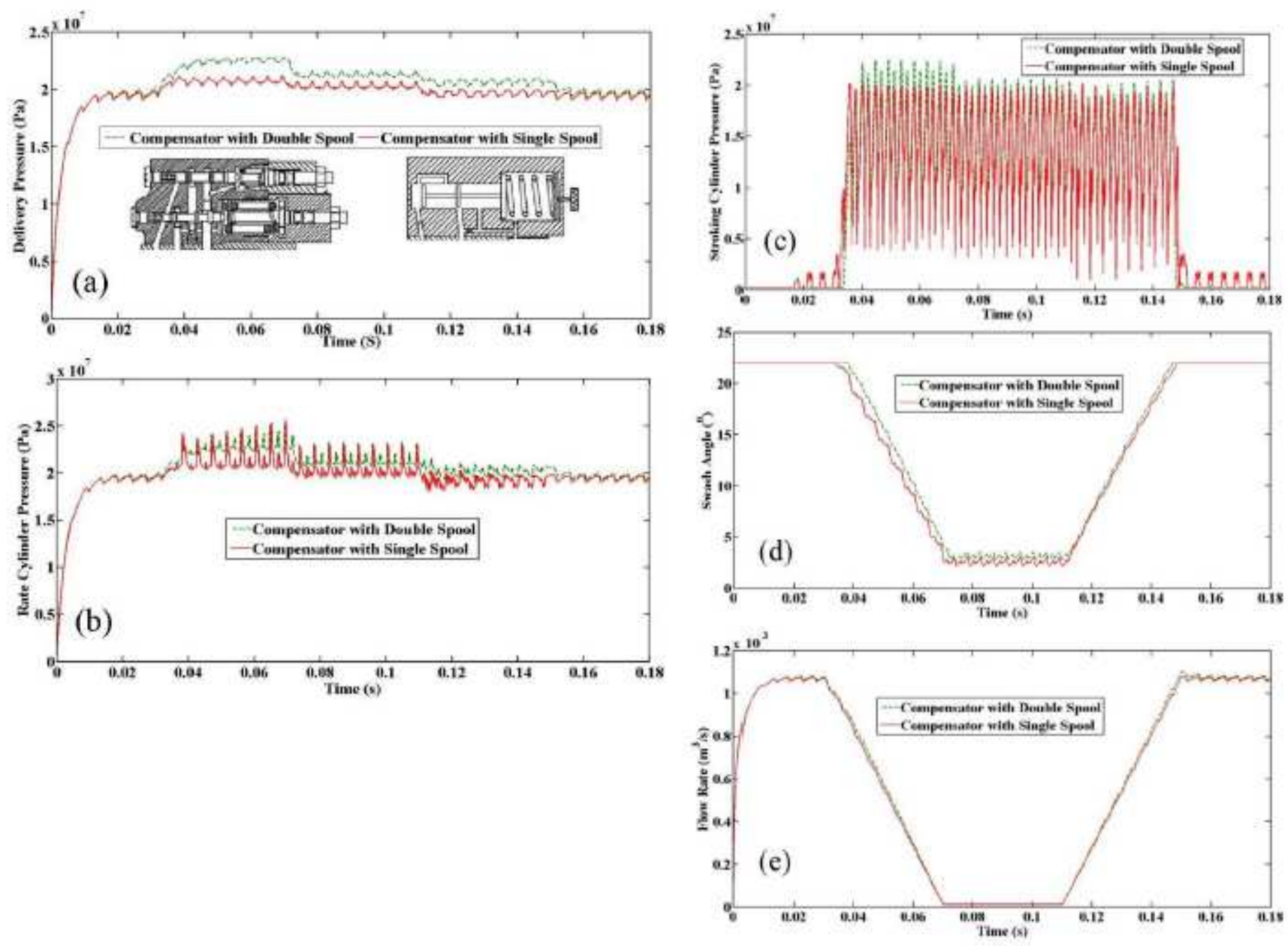

Figure 11

Performance comparisons between two compensators 


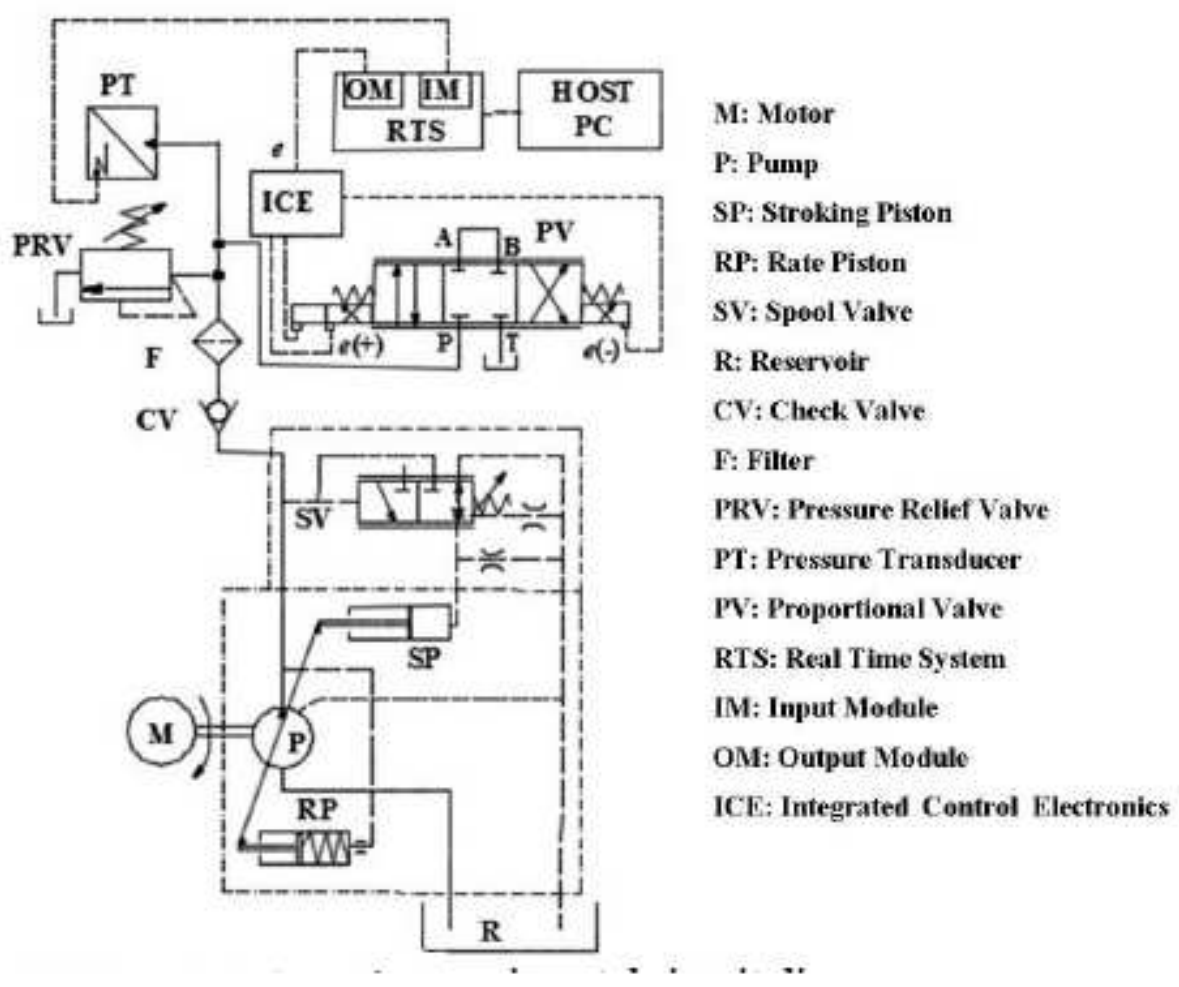

Figure 12

Experimental circuit diagram
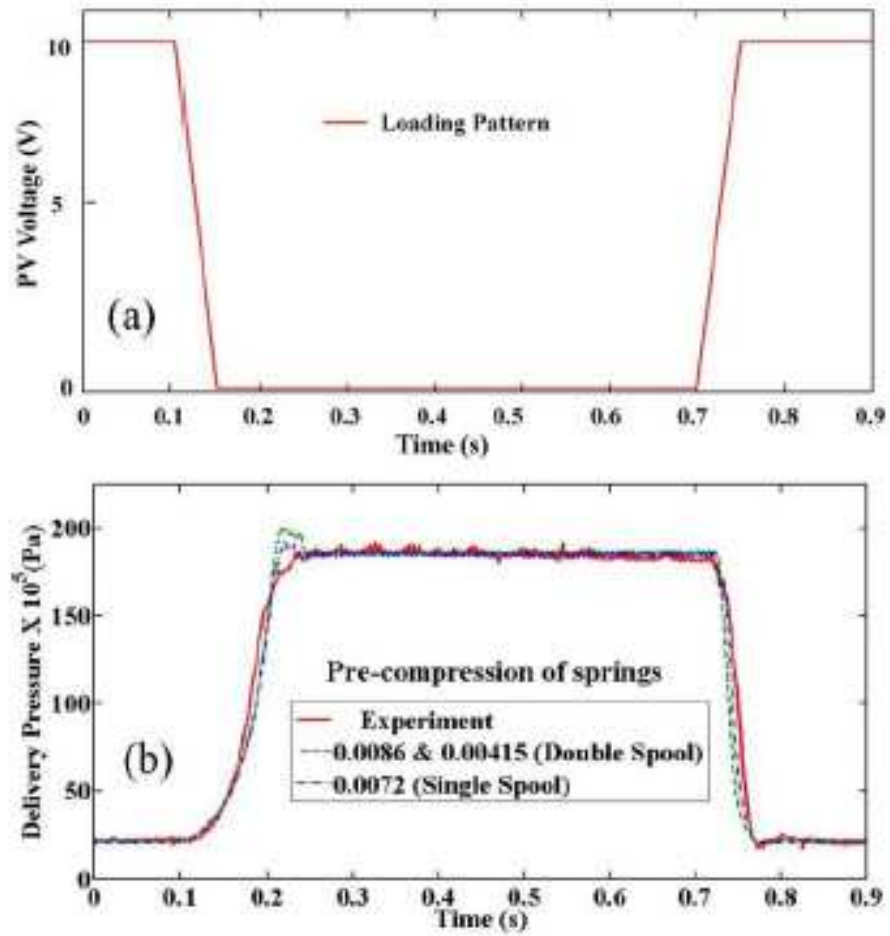

Figure 13 
Experimental and simulation validation for a load variation 